\title{
NASA'S ROLE IN GAS TURBINE TECHNOLOGY DEVELOPMENT: ACCELERATING TECHNICAL PROGRESS VIA COLLABORATION BETWEEN ACADEMIA, INDUSTRY, AND GOVERNMENT AGENCIES
}

\author{
Kenneth L. Suder \\ National Aeronautics and Space Administration, Glenn Research Center \\ Cleveland, Ohio, USA
}

\begin{abstract}
Given the maturity of the gas turbine engine since its invention and also considering the limited and flattened level of resources expected to be allocated for NASA aeronautics research and development, we ask the question are NASA technology investments still needed to enable future turbine engine-based propulsion systems? If so, what is NASA's unique role to justify NASA's investment? To address this topic, we will first review the accomplishments and the impact that NASA Glenn Research Center has made on turbine engine technologies over the last 78 years. Specifically, this paper discusses NASA's role and contributions to turbine engine development, specific to both 1) NASA's role in conducting experiments to understand flow physics and provide relevant benchmark validation experiments for Computational Fluid Dynamics (CFD) code development, validation, and assessment; and 2) the impact of technologies resulting from NASA collaborations with industry, academia, and other government agencies. Note that the scope of the discussion is limited to the NASA technology contributions with which the author was intimately associated, and does not represent the entirety of the NASA contributions to turbine engine technology. The specific research, development, and demonstrations discussed herein were selected to both 1) provide a comprehensive review and reference list of the technology and its impact, and 2) identify NASA's unique role and highlight how NASA's involvement resulted in additional benefit to the gas turbine engine community.

Secondly, we will discuss current NASA collaborations that are in progress and provide a status of the results. Finally, we discuss the challenges anticipated for future turbine enginebased propulsion systems for civil aviation and identify potential opportunities for collaboration where NASA involvement would be beneficial. Ultimately, the gas turbine engine community will decide if NASA involvement is needed to contribute to the development of the design and analysis tools, databases, and technology demonstration programs to meet these challenges for future turbine engine-based propulsion systems.
\end{abstract}

\subsection{INTRODUCTION}

NASA Glenn Research Center (GRC) has played a significant role in gas turbine engine technology development since its inception in 1940 as the Aircraft Engine Research Laboratory. In 1942 the research center became a part of the National Advisory Committee for Aeronautics (NACA) and in 1958 became the NASA Lewis Research Center. More recently, in 1999, it was officially renamed as the NASA John H. Glenn Research Center at Lewis Field. To represent the research and development performed by these research laboratories, the author will refer to them collectively as NASA Glenn Research Center (GRC), irrespective of year the work was performed. Since the patent of the Whittle Engine in 1930, there has been significant progress in the propulsive and thermal efficiency which has resulted in significant reductions in TSFC (thrustspecific fuel consumption), as shown in Figure 1 and Reference [1]. NASA GRC has had a direct role in these aircraft propulsion system improvements through concept development, component testing, analysis, and model development for aircraft engine inlets, fans, compressors, combustors, turbines, and nozzles. Under its charter, NASA Aeronautics Research Mission Directorate (ARMD) does not make, sell, or purchase aircraft engines, but rather NASA's ARMD works independently, as well as with the engine community and other government agencies to develop technologies for the present and the future that enable safer, more reliable, capable, and efficient aircraft with minimal harmful impact on the environment. It is important to note that Figure 1 indicates further fuel burn reductions are attainable, even for the modern Boeing 777 (equipped with General Electric GE90, Pratt \& Whitney PW4000 or RollsRoyce Trent 800 engines). It is also clear that overall efficiency is increased most effectively by simultaneous improvements in thermal efficiency (i.e. core engine technologies) and the propulsive efficiency (propulsor technologies).

Given these turbine engine technology advancements (shown in Figure 1) and also considering NASA aeronautics resources are limited, we ask the questions: Are NASA technology investments still needed to enable future turbine

This material is declared work of the U.S. Government and is approved for public release; distribution is unlimited. 
engine-based propulsion systems? If so what is NASA's unique role? To discuss this topic, we will look at the accomplishments and the impact that NASA GRC has made on turbine engine technologies for the last 78 years from the narrow perspective of this author, based on his vision of NASA's roles and responsibilities. From this author's perspective NASA's primary roles and responsibilities are to a) challenge and inspire students to pursue careers in science and technology, b) set aggressive, yet achievable goals for future generation aircraft that improve performance, safety, and impact on the environment, c) invest in enabling new technologies with potentially high benefit that industry alone would not invest and d) utilize public funds efficiently to develop, demonstrate, and document technologies that benefit the U.S. gas turbine community and all humanity. Critical to these endeavors is the establishment of successful teams and collaborative efforts to understand the flow physics via experiment and analysis, to demonstrate the learning via rig and component testing in a relevant environment, and enhance and validate the design and analysis tools to provide confidence for future missions.

To address the questions of why NASA and what does NASA contribute that is unique, we will review: 1) NASA's role and contributions to turbine engine development from early days of inception to present day, 2) NASA's role in validation experiments and Computational Fluid Dynamics (CFD) code development, 3) NASA's collaborations with academia, 4) NASA's collaborations with other Government agencies, and 4) NASA's collaborations and technology demonstrations that are making their way into products. The scope of the discussion is limited to the NASA technology contributions with which the author was intimately associated and is heavily slanted toward compressor technology development and does not represent the entirety of the NASA contributions to turbine engine technology. The specific research, development, and demonstrations discussed herein were selected to both 1) provide a comprehensive review and reference list of the technology and its impact, and 2) identify NASA's unique role and highlight how NASA's involvement resulted in additional benefit to the gas turbine engine community. Then we will discuss the future challenges for aviation and discuss potential areas for future collaborations, followed by a summary and concluding remarks.

\subsection{BACKGROUND: NASA'S ROLE FROM 1940'S- 1980 'S}

\subsection{Early Years 1940s - 1960s.}

NASA GRC took a leading role in component development in its Compressor and Turbine Division during the 1940s and 1950s. Many single-stage and multistage compressor tests were conducted at the NASA GRC Engine Research Building (ERB), where various design parameters such as blade pressure ratio, aspect ratio, and solidity, were varied to develop an understanding of the trade space to improve fan and compressor performance and operability. The culmination of this early period of compressor testing at GRC was published as a series of classified reports in 1956 and eventually declassified and republished in 1965 as "Aerodynamic Design of Axial-Flow Compressors," NASA SP-36 [2]). A similar publication entitled "Turbine Design and Application", NASA SP-290 summarized the turbine technology during this period [3]. These NASA publications [2] and [3] have provided great value to the compressor and turbine design community for many years and is still considered an authoritative publication on multistage axial turbomachinery design theory and practice.

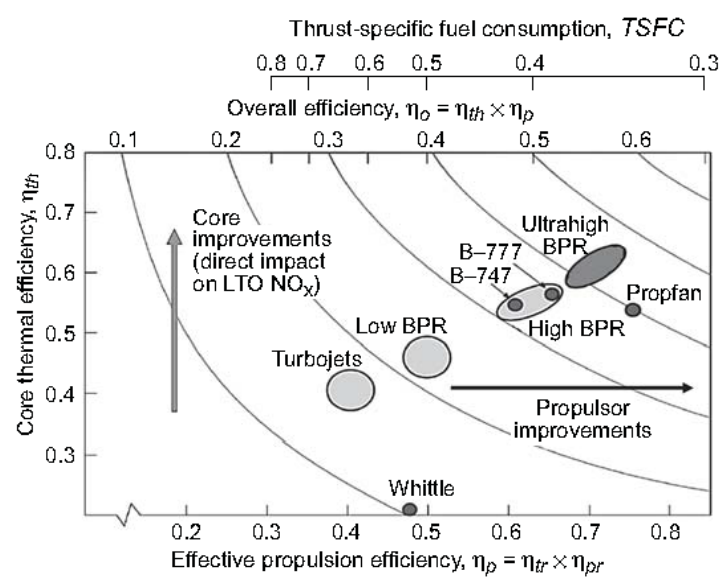

Figure 1. Comparison of historical engine thermal $\left(\eta_{\text {th }}\right)$ and effective propulsion $\left(\eta_{p}\right)$ efficiency improvements. BPR is bypass ratio; LTO, landing and takeoff; and $\eta_{\mathrm{tr}}$, transmission efficiency. Effective propulsion efficiency is the product of the propulsor efficiency $\left(\eta_{\mathrm{pr}}\right)$ and the transmission efficiency $\left(\eta_{\mathrm{tr}}\right)$. (From A.H. Epstein [1].

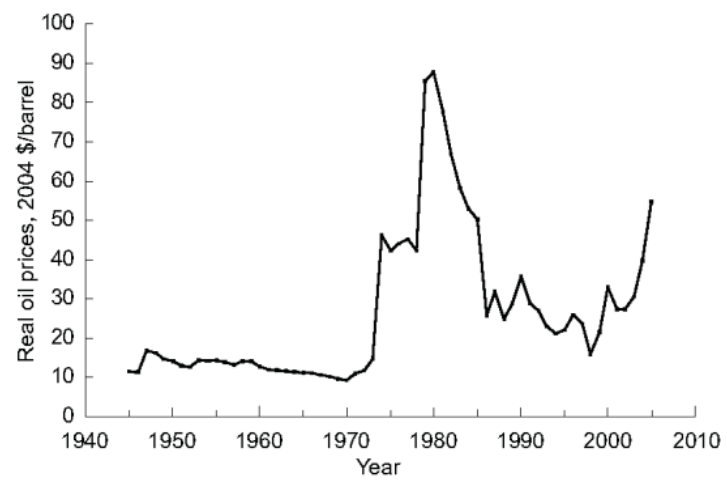

Figure 2. Inflation-corrected oil prices, 1945 to 2005 [4].

\section{$2.21970 \mathrm{~s}-1980 \mathrm{~s}$}

Interest in aircraft fuel efficiency increased dramatically in the 1970s because of the sharp rise in jet fuel prices, largely attributed to the oil embargo by OPEC countries in 1973. Figure 2 shows the inflation-corrected price of oil for the 1945 to 2005 timeframe. In response to this rapid increase in fuel prices, NASA established the Aircraft Energy Efficiency (ACEE) Program in 1975. The goal of the program was to accelerate the development of various aeronautical technologies that would make future transport aircraft up to $50 \%$ more fuel efficient. The baseline engines used for this goal were the Pratt \& Whitney (P\&W) JT9D-7A and General Electric (GE) CF6-50C. The most notable ACEE projects related to engine technology, that were 
led by NASA GRC [4], were the Energy Efficient Engine (E $\left.{ }^{3}\right)$ Project and the Advanced Turboprop Project.

The $\mathrm{E}^{3}$ Project goals were to design a new engine to 1) reduce TSFC by $12 \%$, 2) reduce TSFC performance deterioration by $50 \%$, 3) reduce direct operating costs by $5 \%, 4$ ) meet Federal Aviation Administration (FAA) noise regulations, and (5) meet EPA then-proposed emissions standards as described by Ciepluch et al., [5]. Under the $\mathrm{E}^{3}$ Project from 1975 to 1984 , NASA invested approximately $\$ 200 \mathrm{M}$ in contracts to General Electric (GE) and Pratt \& Whitney $(\mathrm{P} \& W)$. The $\mathrm{E}^{3}$ Project achieved higher propulsive efficiency by using a lowpressure-ratio fan and higher thermal efficiency by using higher overall pressure ratio, higher turbine inlet temperatures, and improved component efficiencies. Specifically, the GE E ${ }^{3}$ effort included a 10-stage, 23:1 pressure ratio compressor, a highly efficient two-stage high-pressure turbine (HPT) and five-stage low-pressure turbine (LPT), and component efficiencies that were significantly above the previous state of the art. Along with increased cycle temperatures, reduced turbine cooling flows were achieved through a combination of materials development and cooling concept improvement - see Davis and Stearns [6]. Many engine core technologies developed under the $\mathrm{E}^{3}$ project were introduced into engine products into the 1990s and beyond. Specifically, GE's large GE90 engine which powers the Boeing 777 aircraft, utilizes a core that was derived from the technologies developed under the $\mathrm{E}^{3}$ Project.

The Advanced Turboprop Project's objective was to investigate incorporating large, unducted propellers as the main propulsor for high-subsonic (Mach number, $M$ approximately 0.8 ) commercial aircraft with a goal of $20-30 \%$ reduction in fuel burn relative to current engines. The challenge was to enable highly efficient turboprop operation at Mach 0.8 flight speeds and higher altitude flight as well as to mitigate the noise issues inherent to unducted configurations, having no nacelle to shield and absorb radiated noise. The technical solution to both the noise and high-speed efficiency problems was to use a swept blade geometry to provide a lower tip Mach number for a given flight speed [4]. Although much progress was made on the development of a viable propfan through both the NASA/Allison/Pratt \& Whitney/Hamilton Standard single rotation concept and the later counterrotating GE "unducted fan" (UDF) concept (Figure 3), various factors kept these concepts from coming to fruition in the market. First, potential negative public perception of propeller engine architectures made the airframe manufacturers reluctant to deviate from their established commitment to turbofan engines, despite the large benefits in fuel burn reduction. Perhaps more importantly, as shown in Figure 1, fuel prices by 1986 had retreated back to nearly pre-1970 values in inflation-adjusted terms. This greatly reduced the urgency for the airline industry to adopt a radical change in engine architecture and ended heavy NASA's heavy investment in unducted configurations by the late 1980s. The idea would however return in the NASA Subsonic Fixed Wing and Environmentally Responsible Aviation (ERA) projects in the mid-2000s coincident with another rapid increase in fuel prices.

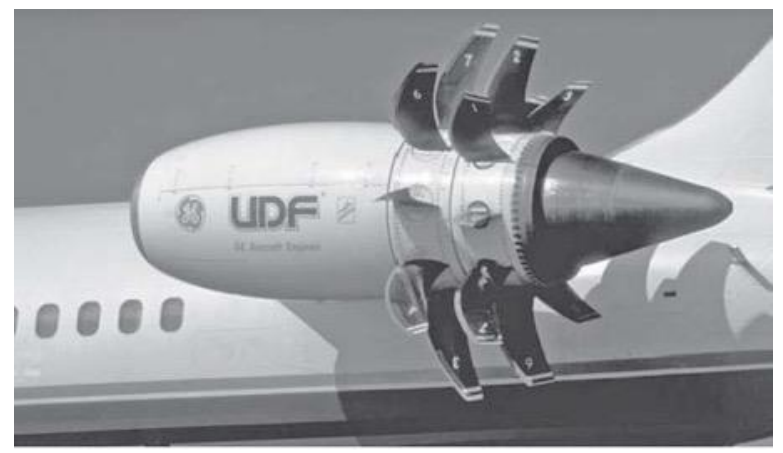

Figure 3. General Electric unducted fan engine. (From http://www.b-domke.de/Aviationlmages/Rarebird/0809.html. Copyright $@$ 2001-2012 by Burkhard Domke. Used with permission.)

\subsection{NASA'S ROLE IN VALIDATION EXPERIMENTS AND FUNDAMENTAL FLOW PHYSICS FOR COMPUTATIONAL FLUID DYNAMICS DEVELOPMENT}

Throughout NASA Glenn Research Center's history, the use of the Center's unique experimental capabilities for compressor and turbine testing and the emphasis on providing return on investment to the Nation on its taxpayer-funded research has resulted in the production of open experimental datasets. In the 1970s and 1980s GRC produced a number of compressor datasets that have been used by the turbomachinery community as a basis for the validation and development of turbomachinery analysis tools, including the growing field of computational fluid dynamics (CFD) codes. Laser Doppler Velocimetry (LDV) was customized to measure the axial and tangential velocity inside the rotating passages of transonic compressors. The transonic fan NASA Rotor 67 was the first major dataset acquired with a single-channel LDV, which captured the shock and wake structure in an isolated transonic fan [7, 8, 9, and 10]. Subsequently, NASA Stage 67 (Rotor $67+$ Stator 67) was the first dataset that captured the unsteady fan rotor/stator blade row interactions with the same single-channel LDV system [11 and 12].

Perhaps the most comprehensive and widely utilized of the NASA datasets is the NASA Rotor 37 data set, having been the basis for the 1994 ASME/IGTI Blind CFD code assessment exercise. This was a period when CFD RANS/URANS codes had limited access to data depicting the flow field in the rotating passages of high speed (compressible) turbomachinery to use for code validation and model development. Building upon NASA's experience acquiring data in NASA fan rotor 67 with a single velocity component system, NASA designed and developed the first laser anemometer measurement system (early 1980's) that acquired axial and tangential velocities simultaneously inside the rotating passages of a transonic compressor. NASA Rotor 37 has an extensive set of aerodynamic probes and LDV data across the rotor operating range from maximum flow to near-stall conditions at $60 \%$ speed (fully subsonic), $80 \%$ speed (transonic), and 100\% design rotor

This material is declared work of the U.S. Government and is approved for public release; distribution is unlimited. 
speed (fully supersonic in the rotor frame of reference). Detailed laser anemometer measurements were acquired at high flow, design flow, and near stall flow conditions at streamwise and radial planes shown in Figure 4. The data are best summarized in $[13,14$, and 15$]$ and the blade design and geometry is provided by Reid and Moore [16].

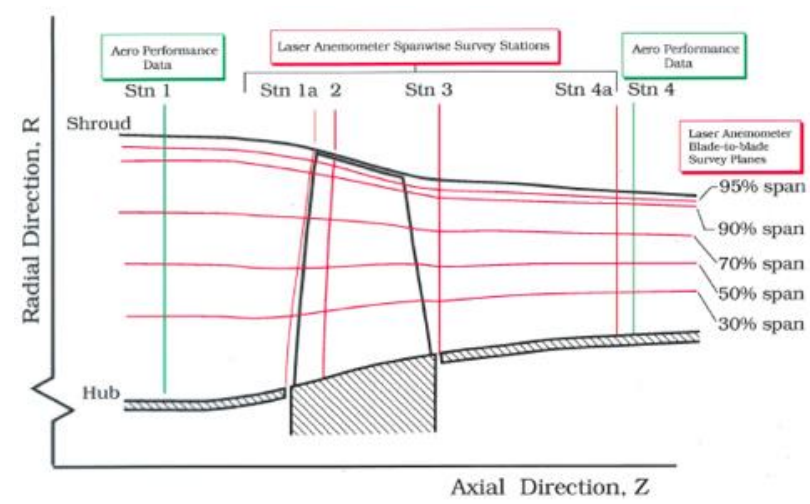

Figure 4. NASA Rotor 37 laser anemometer and aero probe survey locations. From [13].

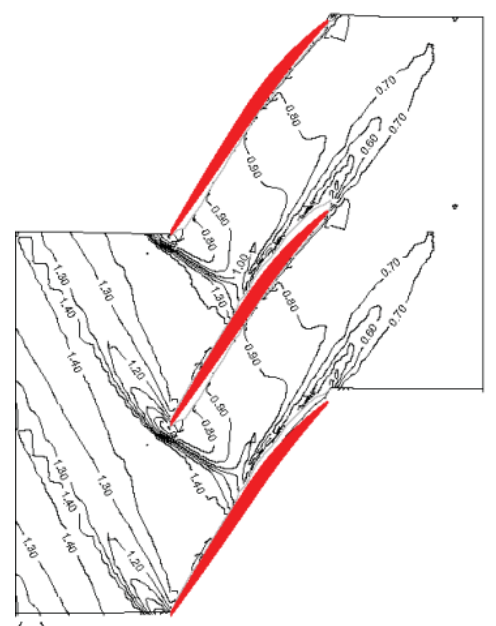

(a)

(b)

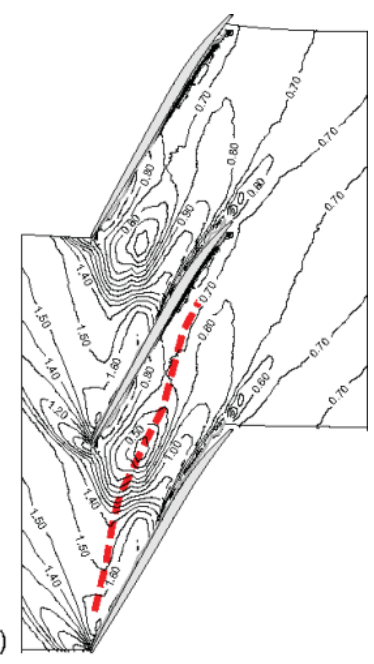

Figure 5. NASA Rotor 37 Laser Doppler velocimetry data contours of relative Mach number at design speed and near stall operating conditon: a) $70 \%$ span stream surface and b) $95 \%$ span stream surface. The red dashed line indicates the tip leakage vortex trajectory. From [13] and [14].

Gas velocity measurements acquired with this laser-based non-intrusive optical instrumentation were used to study the flow physics associated with the shock / rotor tip clearance flow, the shock / boundary layer interactions within the rotor, and wake decay characteristics downstream of the rotor. An example of the measurement detail is provided in Figure 5, which shows the shock boundary layer interaction at 70\% span and shock/tip leakage vortex interaction at $95 \%$ span for a $0.5 \%$ span rotor tip clearance. The attributes of the CFD codes that participated in the ASME blind test case are listed in Table 1. A summary of the
ASME blind test case aerodynamic performance results is presented in Figure 6, which compares the NASA Rotor 37 experimental and CFD results of overall performance at $100 \%$ design speed as well as the radial distribution of pressure ratio, temperature ratio, and efficiency. In summary, many of the CFD code results did not match the experimental data, not only in describing details such as the tip clearance flow, shock structure and rotor wake decay, but also in overall compressor performance and radial distributions of the performance parameters.

Table 1. ASME/IGTI Turbomachinery Blind Test Case Attributes of the 1994 NASA Rotor 37 Test Case Participants.

\begin{tabular}{|c|c|c|c|c|c|}
\hline 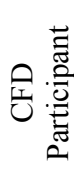 & 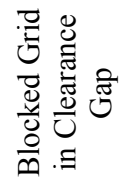 & 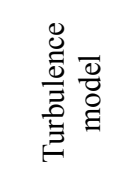 & 总 & 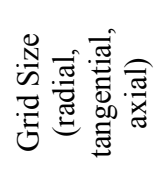 & 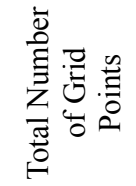 \\
\hline 1 & 7 cells & $\begin{array}{c}\text { Baldwin / } \\
\text { Lomax }\end{array}$ & $\mathrm{H}$ & $26,51,71$ & 101,000 \\
\hline 2 & Modeled & $\begin{array}{c}\text { Baldwin / } \\
\text { Lomax }\end{array}$ & $\mathrm{H}$ & $51,41,132$ & 276,000 \\
\hline 3 & 7 nodes & k-epsilon & I & $51,58,151$ & 447,000 \\
\hline 4 & 7 cells & $\begin{array}{c}\text { Baldwin / } \\
\text { Lomax }\end{array}$ & $\mathrm{C}$ & $41,41,225$ & 378,000 \\
\hline 5 & Modeled & $\begin{array}{c}\text { Baldwin / } \\
\text { Lomax }\end{array}$ & $\mathrm{H}$ & $51,41,132$ & 276,000 \\
\hline 6 & Modeled & $\begin{array}{c}\text { Baldwin / } \\
\text { Lomax }\end{array}$ & $\mathrm{H}$ & $33,33,99$ & 108,000 \\
\hline 7 & Modeled & k-epsilon & $\mathrm{H}$ & $35,30,95$ & 100,000 \\
\hline 8 & 13 nodes & $\begin{array}{c}\text { Baldwin / } \\
\text { Lomax }\end{array}$ & $\begin{array}{l}\mathrm{C}, \\
\mathrm{H}, \\
\mathrm{O}\end{array}$ & $63,46,319$ & $1,050,000$ \\
\hline
\end{tabular}

Following the ASME Blind CFD code assessment study, The Advisory Group for Aerospace Research and Development also used the NASA Rotor 37 benchmark data set to compare results from a large number of Navier-Stokes CFD codes [17]. These test case activities highlighted the large range of results produced by the various codes, some of which is attributable to how the codes were employed in addition to the underlying code algorithms and methods. These discrepancies between the CFD and experimental results have led to significant improvements in CFD mesh generation, turbulence model implementation, and tip clearance modeling. By all means not an all-inclusive list, but References [18-30] highlight the lessons learned and key findings related to the sensitivity of the NASA Rotor 37 solution to the grid, turbulence model, clearance model, and modelling of the gap between the rotor and stationary flow path for various CFD codes. In addition, from 1994-2000 the Rotor 37 data were requested by 88 parties: 55.U.S. / 33 international (10 countries). In addition, the data were requested by the European Research Community on Flow Turbulence and Combustion for CFD 
validation and improvement exercises. Gas turbine engine companies such as Allied Signal (now Honeywell), Allison (now Rolls-Royce), NREC, Pratt \& Whitney, General Electric Aviation, Solar Turbines, Williams International, Continuum Dynamics, Honda, Kawasaki, and Sulzer used this data to validate their in-house and commercial CFD codes enabling them to more confidently design fans, compressors, and turbine engine components. To this day, these data are used as a CFD validation tool and are referenced by presenters annually at the ASME IGTI Turbo Expo conference.
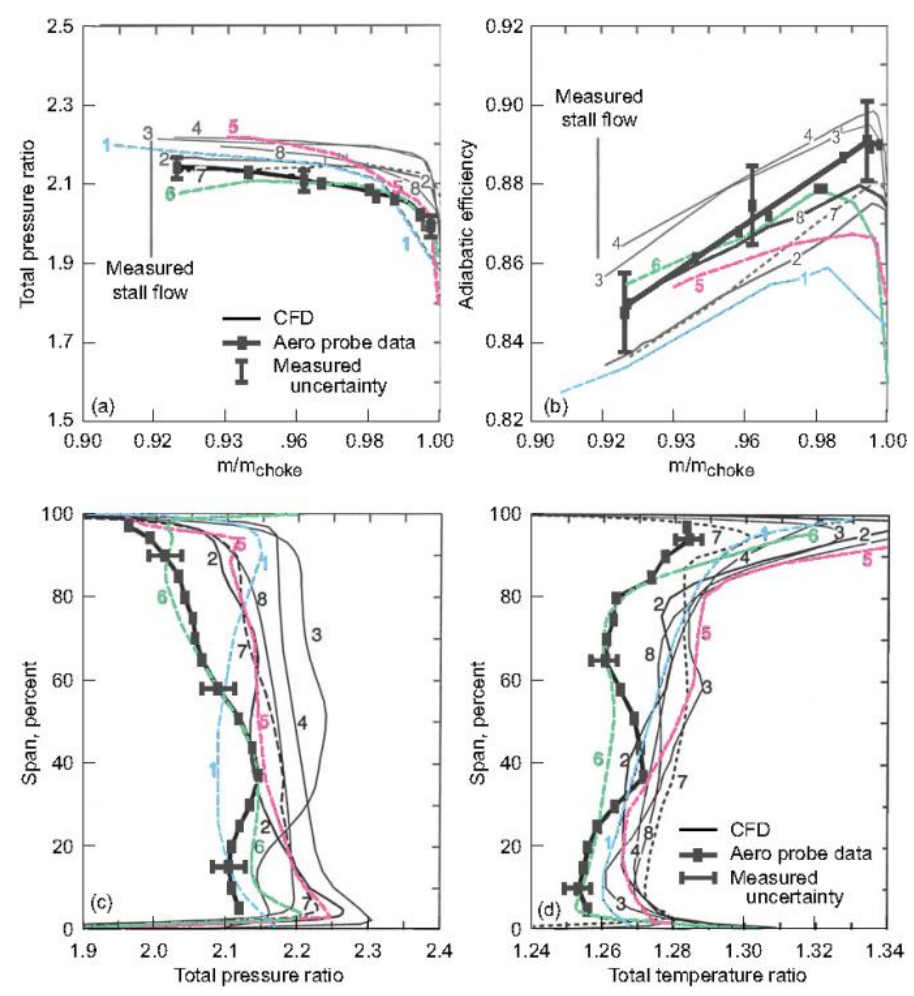

Figure 6. NASA Rotor 37 American Society of Mechanical Engineering blind test case results (1994). CFD is computational fluid dynamics, $m$ is the mass flow and $m_{\text {choke }}$ is the choking mass flow rate. From [13].

Additional experimental test cases produced by GRC include the NASA Stage 35 [31] which incorporates a full compressor stage versus the rotor-only approach of the rotor 37 test case. In addition, NASA built a 5-foot diameter $(1.524 \mathrm{~m})$ centrifugal compressor in which to make detailed probe and optical measurements for code validation - results are summarized in [32]. Centrifugal compressor scaling studies [33] and code validation datasets [34] were used to improve centrifugal compressor CFD codes and the resulting designs. In the turbine area, an example of one of the widely employed test cases is the NASA Transonic Cascade Heat Transfer dataset [35 and 36], which has been used to validate turbine heat transfer tools across the community. As an example of how it was used, these end wall heat transfer data were instrumental in the development and assessment of the $v^{2}-f$ and Spalart-Allmaras turbulence models [37].

NASA has also directly contributed to CFD analysis improvement through the development of NASA in-house turbomachinery codes that have contributed to the body of knowledge in the field. A prime example of this contribution is the APNASA code [38], which was developed, debugged, and tested inhouse on a number of NASA developed geometries. This Navier-Stokes code offers the ability to accurately model the deterministic impact of blade rows throughout a multistage turbomachine without the massive time and expense that would be required to resolve the unsteady full-wheel flowfield for all stages. This is particularly important for multistage compressors, where such an unsteady calculation would be prohibitive, even with today's computers. The APNASA code has been distributed to the U.S. aircraft and industrial gas turbine industry and is in common use today. Other NASA-sponsored Navier-Stokes CFD codes that have made a substantial impact on the turbomachinery analysis field include Glenn-HT, TURBO, H3D, ADPAC, and SWIFT. The Glenn-HT code development has focused on turbine cooling and heat transfer applications. It has incorporated the ability to resolve the complicated turbine cooling passages and film cooling holes to increase turbine inlet temperatures. Several first-of-their-kind demonstrations of turbine heat transfer analyses have been carried out using the Glenn-HT code including internal passage heat transfer, film-cooled external heat transfer, and turbine tip clearance heat transfer. The TURBO code was developed under GRC funding and enables full unsteady Navier-Stokes simulations of multistage compressors and turbines. This kind of unsteady analysis capability has found excellent application in studying the impact of distorted inlet flows on downstream fan aerodynamic performance as well as in evaluating the impact of unsteady blade row interactions on compressor and turbine performance.

APNASA, TURBO, Glenn-HT, H3D, and SWIFT were all recently validated against NASA rotor 37 and NASA stage 35 test cases as part of a NASA turbomachinery code assessment activity. The results were reported at the 2009 AIAA Aerospace Sciences Meeting in References [39-43]. The results indicated strong agreement among the codes for compressor speedline and stall. However, to better predict the radial distribution of the compressor performance parameters required using advanced modeling techniques such as unsteady Reynolds-averaged Navier-Stokes equations, large eddy simulation, and accurate resolution of the geometry to capture the impact of secondary flow features on the performance. NASA CFD developments and applications to turbomachinery problems have contributed significantly to turbomachinery flow physics insight from synergistic computational and experimental investigations. Turbomachinery flow physics features such as shock structure, tip leakage flows, turbine cooling flows, blade row interaction, stall inception and flow control have been studied and better understood through GRC efforts. 


\section{WHY NASA? NASA flexibility to explore beyond orignal scope to maximize learning and provide reliable benchmark data sets for the turbomachinery community - the untold story behind the NASA Rotor 37 benchmark dataset.}

NASA is in a unique position to solve unforeseen problems and explore research opportunities that arise, but are beyond the funded scope of the original project. As an example, we will discuss some of the main issues that were encountered during the data acquisition of NASA Rotor 37 blind test case data that not only required more time and resources, but also led to future research and valuable learnings. These learnings were then disseminated to industry and academia through publications or collaborative efforts.

Beyond the obvious need to devleop a laser anemometer system to simultaneously acquire the axial and tangential velocities upstream within and downstream of a transonic compressor, other issues arose that required approximately six years (1987-1993) to acquire the data and ensure that the data was accurate, repeatable, and consistent with itself and the conventional aerodynamic probe measurements of pressure, temperature, and flow angle. The following major issues were encountered: 1) oil leakage from the test rig would accumulate on the optics window that would reduce or eliminate the ability to acquire data, 2) humidity effects would allow seed particles to agglomerate, resulting in particles that were too big to follow the flow through shocks and shear layers, 3) seed particles would accumulate on the blade surface resulting in measurable performance changes that were traceable to changes in the passage shock structure. New operating procedures were developed to address these issues: 1) significantly reduce oil leakage by manually adjusting pressures across the various seals, 2) add dry air capability to reduce humidity effects or test under dry atmospheric conditions, 3) repeat data at the design speed choke condition and assess repeatability of performance and shock positions, 4) measure the rotor shock structure at the tip for the given operating condition of that test day and verify it's repeatability, 5) make the seed particles in house and validate their size and uniformity, and 6) clean the blades weekly or whenever differences in shock structure or performance were noted.

As a result of the issues addressed in the previous paragraph, much of the data had to be repeated on several occasions in large part due to the sensitivities of the transonic compressor to incidence angle and blockage resulting from flow separations, shock-boundary layer interactions, tip clearance flows, etc. Unfortunately, it wasn't until we discovered the flow field structures and/or performance were not repeatable that we realized something had changed and an investigation ensued to determine root cause. Furthermore, it was critical that the geometry of the NASA rotor 37 had to be well documented. Therefore, much effort was taken to validate the incidence angle and blade tip geometry untwist at design speed - see Figure 7 . Blade leading and trailing edges were measured with the laser system on a routine basis. It was also necessary to assess the variances in the blade geometry across the 36 passages and to understand the passage-to-passage variability on the ensemble averaged results - see Figure 8 .

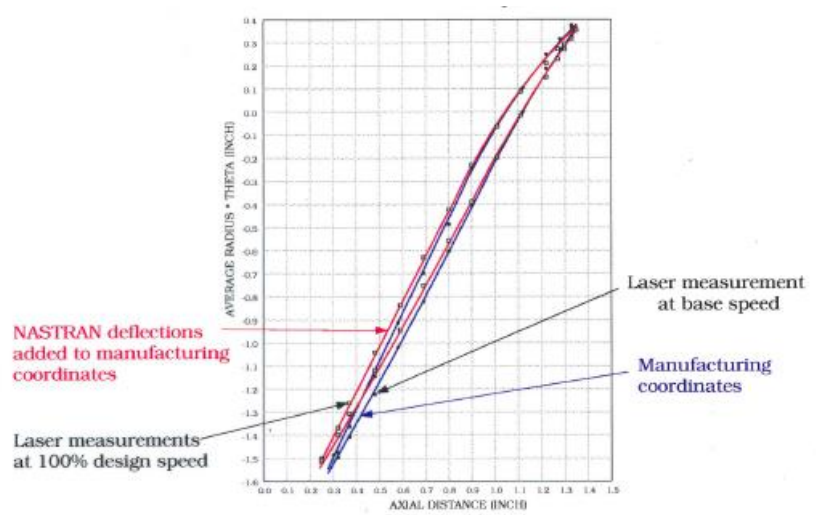

Figure 7. NASA Rotor 37 - Validation of rotor blade tip geometry (plotting axial vs circumferential distance) and measurement of blade tip untwist under load at $100 \%$ design speed at the blade tip . From [13].

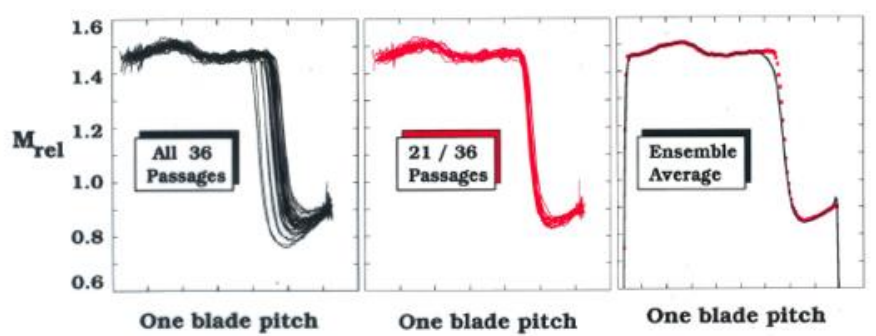

Figure 8. NASA Rotor 37: Impact of passage to passage flow field variations on the Ensemble average where black is for all passages and red is using 21 of 36 passages. From [13].

Once all of these sensitivities were understood and the LDV data were repeatable and consistent with that from the aerodynamic probe, it was necessary to withhold the data for over a year. Only three NASA employees had access to the data during this entire time period to ensure the data was truly a blind test case. Those three personnel acquired and analyzed the data, and exercised various CFD codes to deteremine the proper plotting scales for all of the parameters that were being compared for the ASME blind test case. This was a significant effort, but in the end provided a reliable benchmark dataset which provided a true assessment of the state of CFD codes at that time. It is this author's opinion that there are many types of validation data sets used to develop models, but a true assessment of the tools and methods can only be performed with a true 'blind' test case.

The first major issue was the development of the first laser anemometer system to simultaneously measure the axial and tangential velocity components upstream, within, and downstream of a transonic compressor. The previous singlecolor laser systems utilized seed particles that fluoresced a color different than the laser light; thereby allowing filters to reject the reflected light from the hub and rotating blade surfaces. However, for the simultaneous axial and tangential velocity measurements a two-color laser system required collecting the scattered light from each color. Due to the large number of 
reflections from the metallic blades and flowpath surfaces that contaminated the desired light scattered from the seed particles following the flow, it was decided to apply anti-reflective black paint $(0.025 \mathrm{~mm}$ thick) on the hub and blade surfaces of NASA Rotor 37. The paint worked well in that it minimized the reflections. Unfortunately, the baseline performance of the compressor was drastcially reduced resulting in a loss of 6 points in efficiency and a 9 percent reduction in pressure ratio at the design operating point [44]. Was this performance change due to a modification of the blade leading edges, adding thickness on the blade surface, and/or to the additional surface roughness inherent to the antireflective paint. To separate the effects of thickness and roughness a smooth coating of equal thickness was applied to the blade and hub surfaces. Speedlines were mapped at $60 \%$ (subsonic), $80 \%$ (transonic), and 100\% (supersonic) design speeds - see Figure 9. The smooth coating resulted in a performance degradation of about half that observed with the rough coating. Subsequently, each coating was applied to different regions of the blade surface to determine which portions of the airfoil were most sensitive to the thickness/ roughness variations. The results indicated the thickness/roughness over the first 2 percent of blade chord accounts for virtually all of the performance degradation for the smooth coating, compared to about $70 \%$ for the rough coating see Figures 10 and 11.

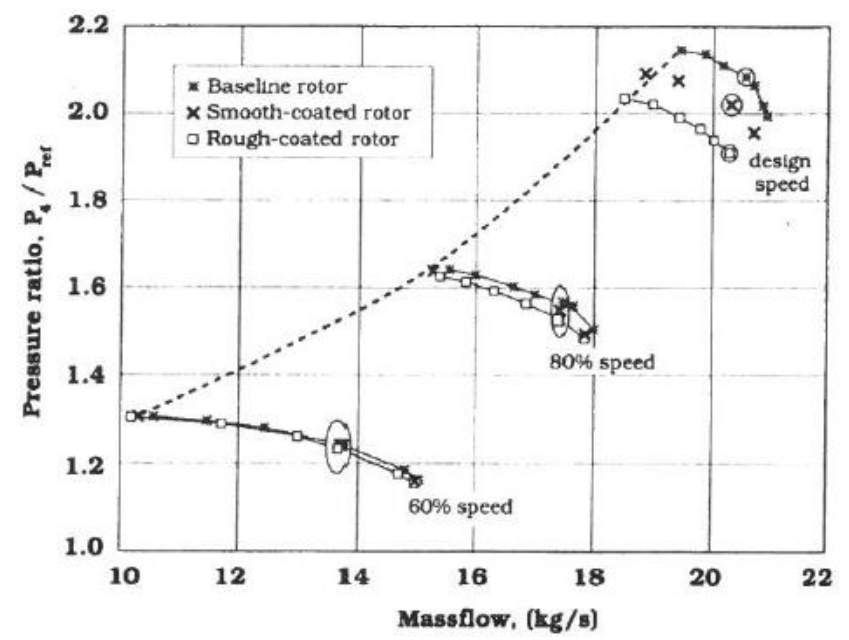

Figure 9. NASA Rotor 37: Pressure rise characteristics for the full coverage coatings; circled data points indcate operating conditions where radial surveys and laser anemometer data were acquired. From [44].

To understand the flow physics associated with these performance impacts, detailed laser anemometer measurements were made at $70 \%$ span for the baseline blade and the coated configurations at the design point - see Figure 12. The shaded area in the lower blade passage in each contour plot indicates the area downstream of the shock where the relative Mach Number is greater than 0.9. The inset shows the shock location as defined by the relative Mach number contour level of 1.3. The Mach number distributions upstream of the shock are similar. The passage shock angle is slightly more oblique for the baseline case which is attributed to the baseline data being acquired at a slightly higher mass flow than the coated configuations (see Figure 9). The similarities in the flow field ahead of the shock are consistent with the fact that the mass flow and incidence angle is nearly the same for all three cases. The pressure rise across the shock accounts for much of the pressure rise across the rotor and the loss in pressure rise for the coated cases must therefore be due to the changes in the flow field downstream of the shock. Both coated cases display a more prominent lambda shock footprint near the suction surface than the baseline case, followed by a region of low Mach number along the suction surface downstream of the shock impingement point. This indicates the shock/boundary layer interaction generates a larger region of low momentum fluid near the suction surface for the coated cases. This additional blockage downstream of the shock results in less diffusion and higher Mach numbers in the rear of the blade passage as shown by the shaded regions in Figure 12. This is more clearly shown in Figure 13 which shows the Mach number along the mid-pitch line at $70 \%$ speed. The main difference between the coated and baseline cases is the levels of reacceleration and subsequent diffusion downstream of the shock. The higher Mach number at the trailing edge and the decrease in diffusion across the blade is consistent with a reduction in pressure rise. More details are provided in [44] where it is shown that a blockage increase of only $1.5 \%$ was responsible for the large degradation in performance measured between the baseline and coated blade configurations.

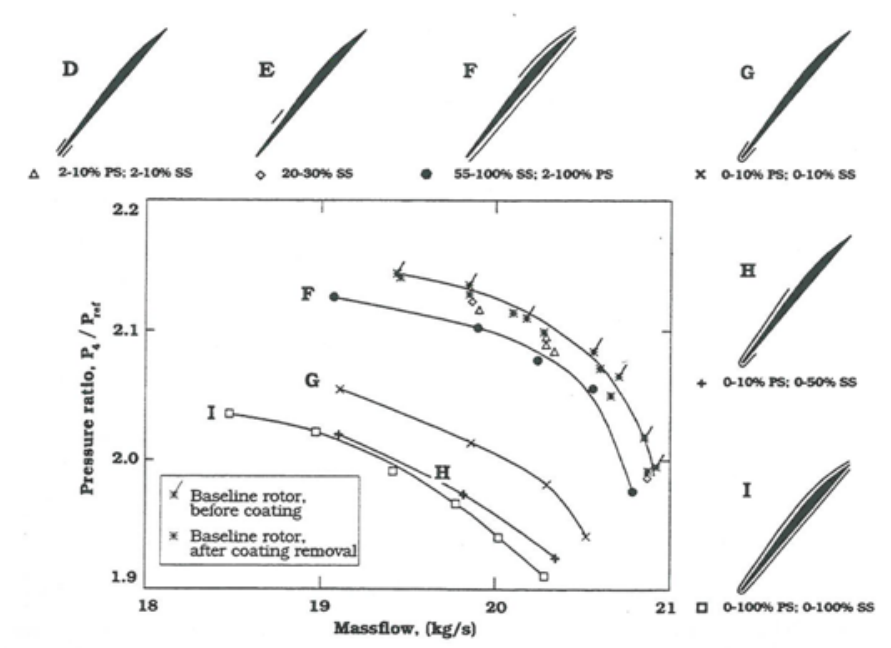

Figure 10. NASA Rotor 37: Pressure rise characteristics for the rough coatings at design speed. From [44].

These results highlighting the sensitivity of highly loaded transonic fans/compressors to leading edge shape, incidence angle, and blockage, led to several other studies on blade refurbishment practices such as those in References [13 - 15, and 44 - 47]. These results provided guidance to airlines on changes to existing blade refurbishment practices, which lead to reduced Specific Fuel Consumption (SFC) and reduced Exhaust Gas Temperature (EGT), thereby resulting in more time on the wing 
between engine overhauls. Furthermore, the research results in [44] prompted the first-ever back-to-back full-scale engine test comparing Rolls-Royce RB-211 engine performance before and after blade refurbishment to quantify the effect of the blade restoration processes. Delta Airlines and Sermatech International participated in this exercise. This research resulted in a reduction in airline operating cost through fuel savings of 35000 gal per year per engine and three months more time on the wing for an engine which, if implemented on fans of high-bypass ratio engines, results in a cost savings of \$30K (1990 USD) per engine to the airlines (according to Delta Airlines).

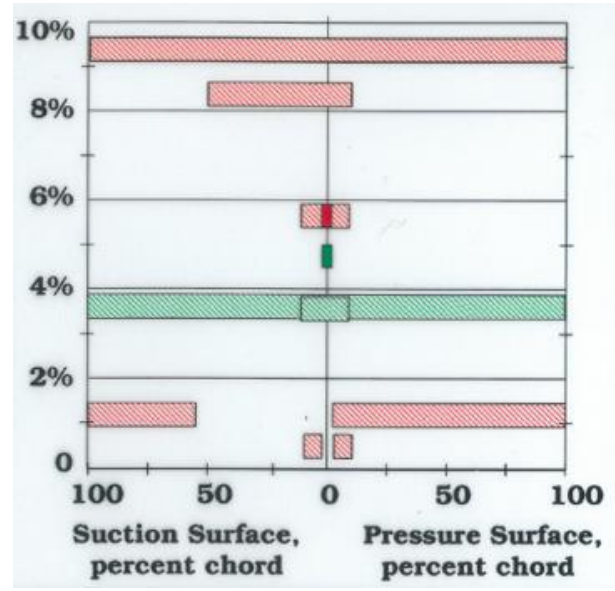

Figure 11. NASA Rotor 37: Pressure ratio degradation relative to blade surface area covered by smooth (green) and rough (red) coatings at the design speed mass flow of $20.3 \mathrm{~kg} / \mathrm{s}$. From [44].
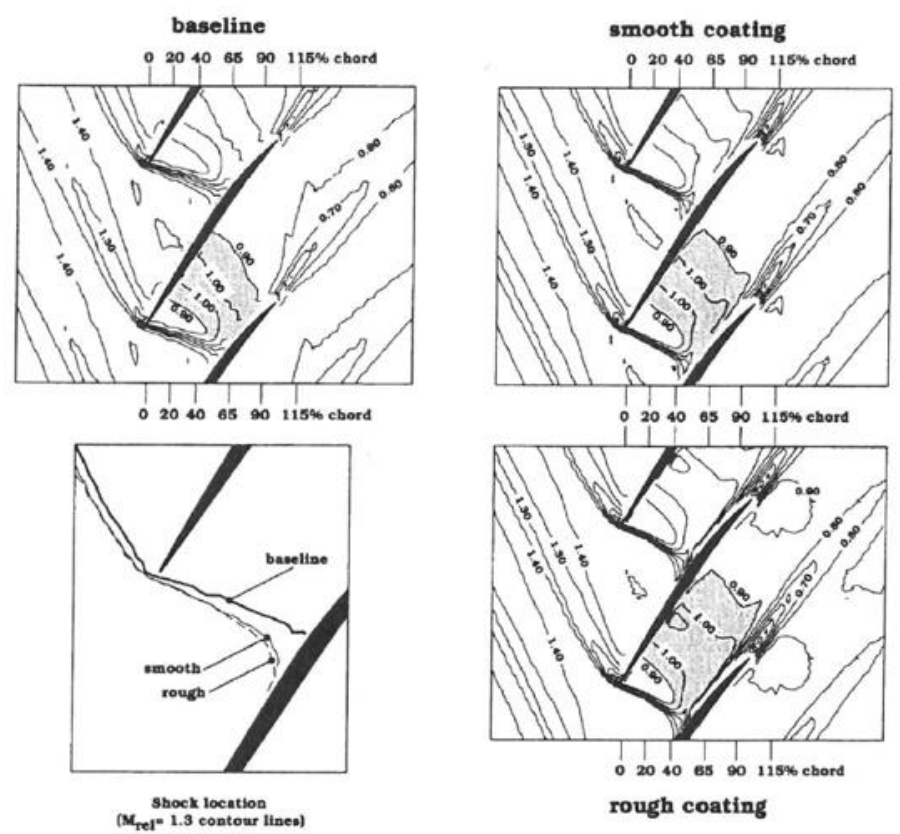

Figure 12. NASA Rotor37: Laser anemometer measurements of relative Mach Number on the $70 \%$ span stream surface. At the aero design point. From [44].

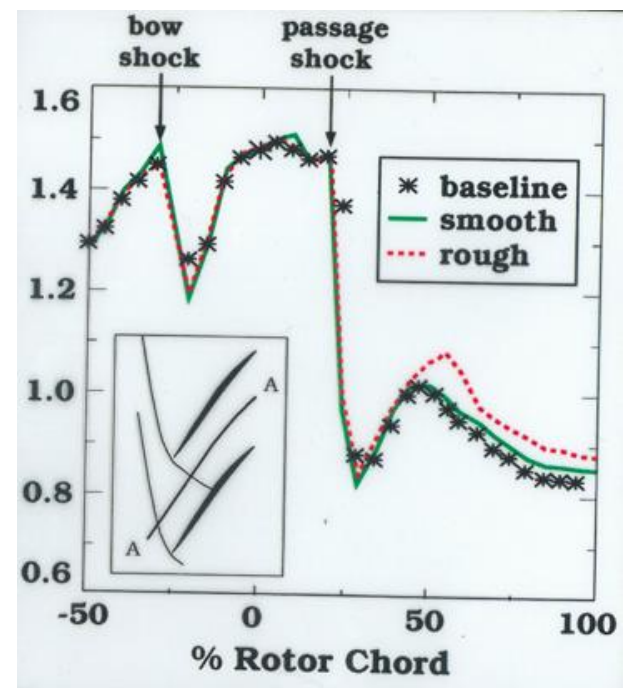

Figure 13. NASA Rotor 37: Laser anemometer measurements of relative Mach Number along the mid-pitch line, A-A, at $70 \%$ span at the aero design point. From [44].

\subsection{NASA COLLABORATIONS WITH ACADEMIA - EXAMPLE: STALL LINE MANAGEMENT (1994- 2004+)}

NASA, as part of its mission, has consistently invested in universities and student development either via summer internships, grants, scholarships, and more recently NASA Research Announcements (NRAs). NASA recently funded a set of NASA Research Announcement awards focusing on better understanding and mitigating turbine and compressor tip clearance flows, which can enable reduced aerodynamic loss and increased pressure ratio cycle engines. These NRAs are also producing experimental data for use in computational fluid dynamics validation efforts across the turbomachinery community- see References [48-50].

In the 1980's-2000's it was quite common for Masters and Ph.D. students to utilize NASA test facilities to conduct their research. As an example of how these collaborations can grow into long-term technology development efforts, the author will highlight a collaborative effort between the MIT Gas Turbine Laboratory and controls group with the NASA turbomachinery and controls branches. This effort started out as a MIT Ph.D. student desiring to use a NASA high speed compressor test facility to demonstrate active flow control strategies to enhance compressor stability using mass injection. Mass injection upstream of the tip of a high-speed axial compressor rotor is a stability enhancement approach known to be effective in suppressing stall in tip-critical rotors. Measurements were acquired in the NASA Glenn single-stage axial-flow compressor facility. The rotor tested, designated NASA Rotor 35, had 36 blades, an inlet tip radius of $25.4 \mathrm{~cm}$, a hub-tip radius ratio of 0.70 , an aspect ratio of 1.19 , a tip solidity of 1.3 , and an axial chord of $2.72 \mathrm{~cm}$ at the tip and $4.12 \mathrm{~cm}$ at the hub. The compressor was designed for axial inlet flow with an inlet relative Mach number of 1.48 at the tip at the design speed. The

This material is declared work of the U.S. Government and is approved for public release; distribution is unlimited. 
rotor tip clearance at the design speed is $0.86 \%$ of tip chord. The compressor aerodynamic design and blade coordinates were reported by Reid and Moore [16]. An array of 12 discrete tip injectors equally spaced around the annulus and located 2 axial chords upstream of the compressor (shown in Figure 14) were used to demonstrate the first success at controlling rotating stall in a high-speed compressor subject to severe inlet flow distortion - both radial and circumferential inlet distortion. This research demonstrated substantial extension of compressor operating range (30\%-50\% reduction in stalling mass flow) using steady and unsteady actively controlled air injection at the rotor tip. Refer to Figure 15 and Weigel et al [51] and Spakovszky et al [52] and [53], respectively.

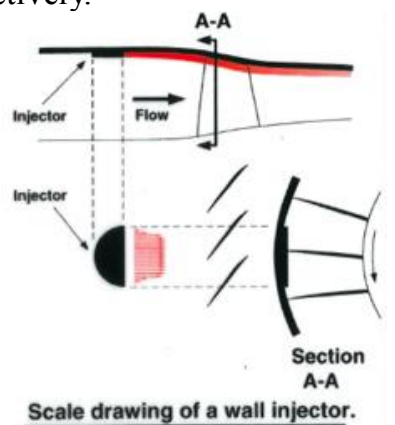

Figure 14. Wall injector schematic - injector located 2 chords upstream of NASA Rotor 35. From [51].

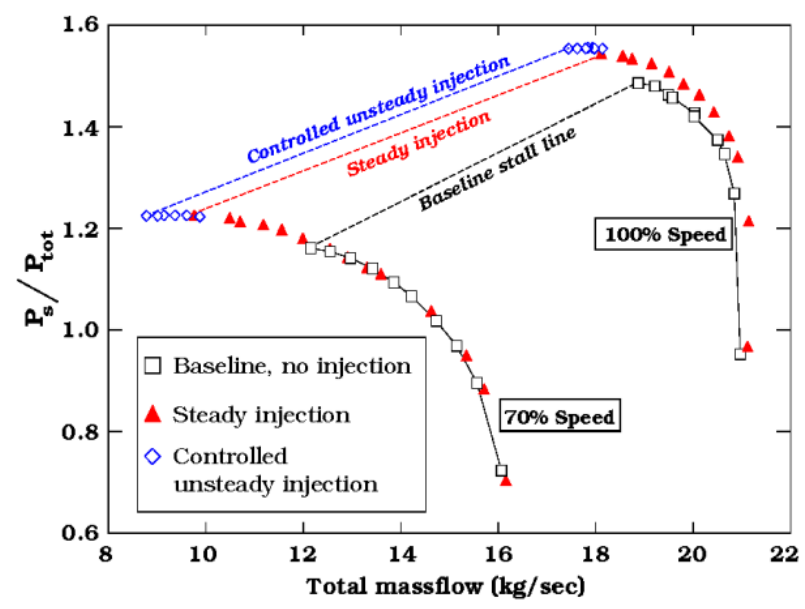

Figure 15. Impact of steady and controlled injection on the stability line - measured by Weigl et al [51].

Using the same experimental configuration, NASA conducted a parametric study of injector spacing, injector design, injector flow rate, and injector momentum to identify key parameters for compressor range extension using steady injection [54]. A major goal was to reduce the amount of injected flow, since in practice it is downstream flow that the compressor has already worked to a high pressure. From analyzing the computational and experimental results, it was concluded that tip injection decreases incidence and blade loading at the tip, allowing increased loading at lower blade spans before the blade stalls. With tip injection present, the blade stalls when the loading at the tip reaches the level equal to that for which the blade stalls with no injection. Furthermore, the results indicated that nearly the same level of stability enhancement could be achieved with a $75 \%$ reduction in injector mass flow - see Figure 16. Note the half-height injectors provided half the flow area of the full height injectors; thereby resulting in a doubling of the jet velocity for the half-height injectors for the same amount of mass injection. Therefore, a comparison of points A, B, C, and D in Figure 16 shows that range extension is not correlated with mass or momentum of the injected flow, but rather with the increase in mass-averaged axial velocity at the tip. The maximum range extension is achieved when the injectors are choked. Furthermore, it is shown that when fewer than four injectors are used, the ability to increase the mass-averaged axial velocity at the tip begins to diminish due to the reduced circumferential coverage.

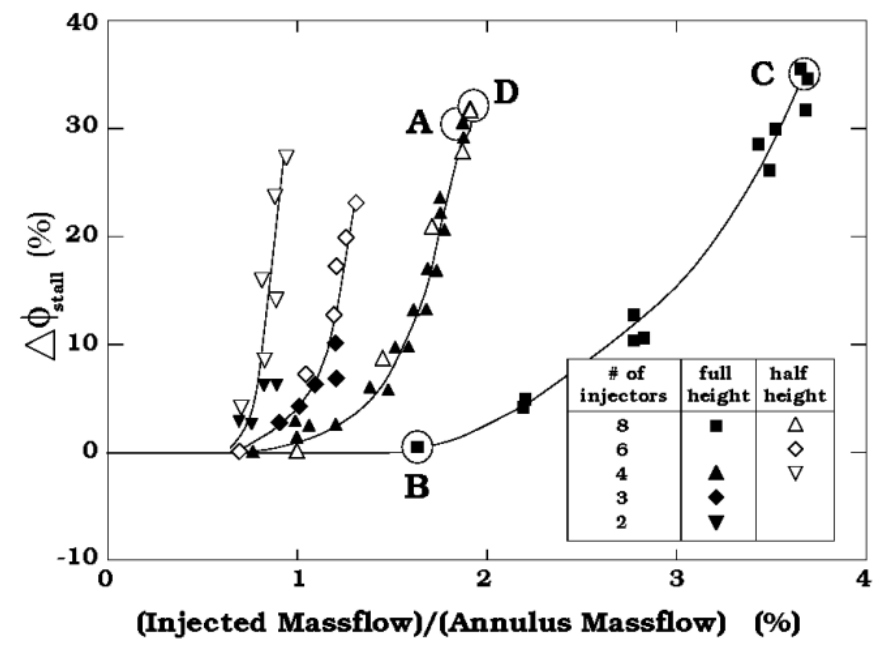

Figure 16. Compressor normalized stall range extension versus injected mass flow measured at $70 \%$ speed for half-height and full-height injectors. From [54].

In Figure 17 it is shown that for a fixed number of injectors, a 6-fold change in reduced frequency yields the same range extension. Therefore, another major conclusion from this work was that range extension is related to the total circumferential extent of injection but is not related to the circumferential arrangement of injection locations. Using this knowledge, tip air injection schemes can be optimized to produce maximum enhancement using the least amount of air; thereby minimizing the inherent penalty associated with recirculating air in an actual engine application. The next steps were to verify that tip injection would work in a multistage compressor, first with external air followed by recirculating air within the compressor.

Subsequently, the use of discrete tip injection to replace variable inlet guide vane scheduling in a highly-loaded multistage compressor to maintain stall margin at part-speed conditions was demonstrated for the first time in a two-stage high speed fan - see Figure 18. Removing variable guide vanes 
reduces engine weight and complexity, thereby reducing the purchasing and maintenance costs [54]. Following the success of tip injection in a two-stage fan, the potential for using end wall recirculation to increase the stability of transonic highly-loaded multistage core compressor was investigated using a six-stage aero engine development compressor that was designed to replace a nine-stage production unit. Refer to [55]. Since the injectors were not designed for high temperatures, the recirculation was simulated by injecting cooler air while simultaneously bleeding the appropriate amount of air downstream. This configuration is illustrated in Figure 19. Though stall margin enhancement was demonstrated, more improvement in performance and operability came from an improvement in matching of the stages rather than a reduction in the stalling mass flows; thereby, showing that recirculation has the ability to independently throttle individual stages in a multistage compressor. Finally, recirculation was demonstrated on a high speed compressor stage as shown in Figure 20 and discussed in detail in [55].

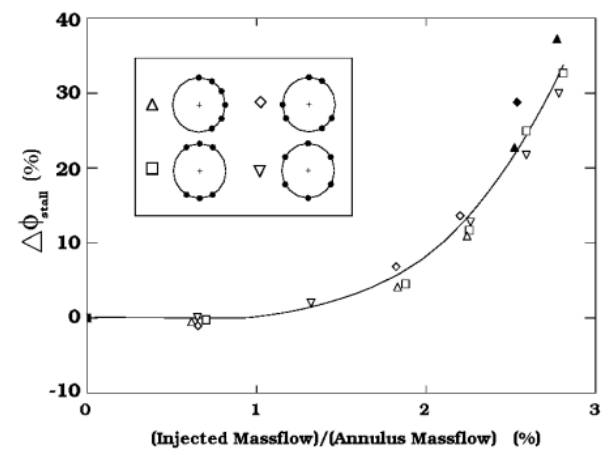

Figure 17. Range extension measured at $70 \%$ speed as a function of injected mass flow for various arrangements of six injectors around the annulus. From [54].

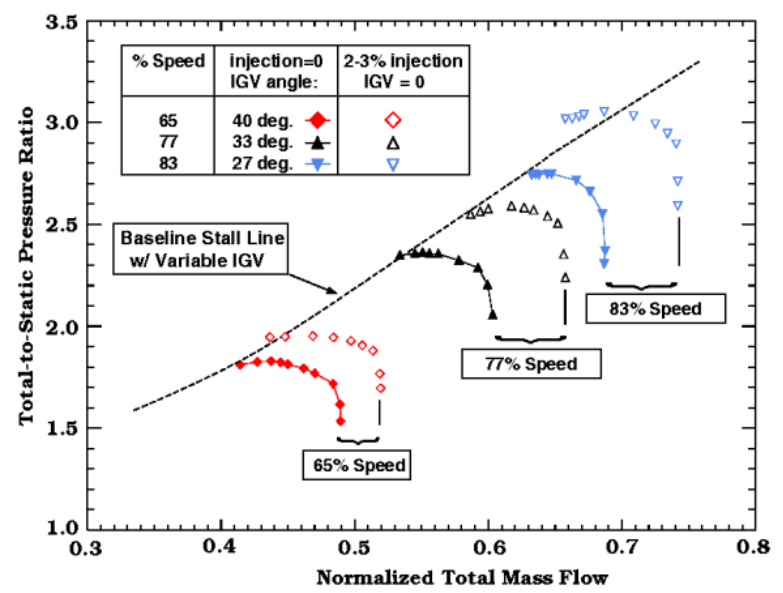

Figure 18. Part-speed performance characteristics of a twostage high speed fan with and without tip injection. Solid symbols: nominal IGV schedule with no tip injection. Open symbols: IGV fixed at 0 degrees (axial) with tip injection. From [54].

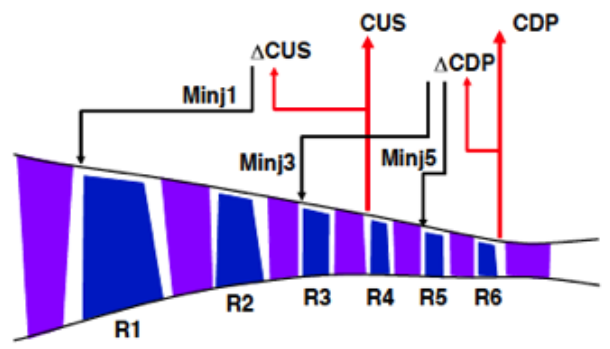

Figure 19. Schematic representation of simulated recirculation in the multistage compressor. Customer bleed, CUS, is incremented by an amount $\triangle$ CUS to account for mass flow Minj1 injected into R1, and compressor discharge bleed, CDP, is incremented by an amount $\triangle \mathrm{CDP}$ to account for mass flows Minj3 + Minj5 injected into Rotors 3 and 5. From [55].

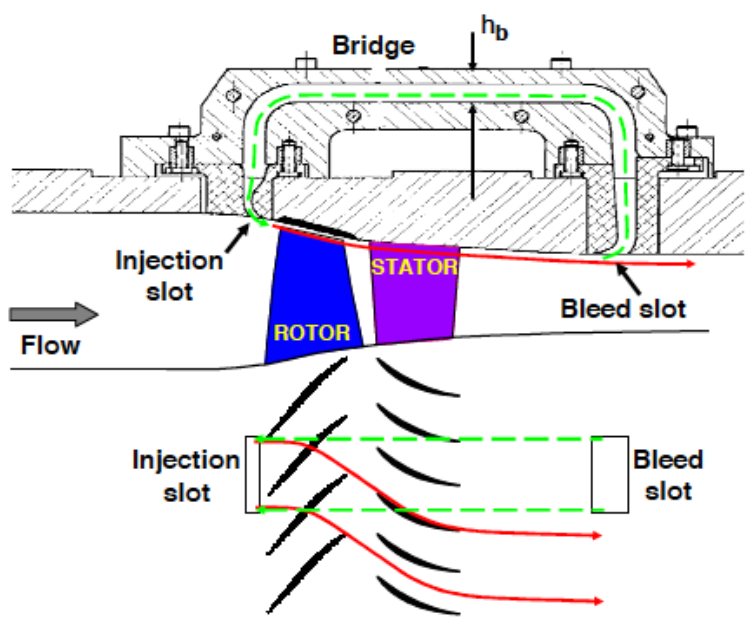

Figure 20. Scale drawing of the recirculated flow through the single stage compressor. Green indicates the path of bleed air through the bridge; red indicates the path of injected air through the stage. From [55].

\section{WHY NASA? NASA flexibility to create and leverage collaborations to continue technology development from theory to engine component demonstration.}

In conclusion, this collaborative research activity blossomed into a progression of technology developments from 1994-2005. A MIT/NASA collaboration to demonstration active stall control in a single stage compressor evolved into study using multistage compressors with uncoupled injection and recirculation, to ultimately employing fully coupled recirculation and injection. What was initiated as a simple validation experiment expanded into a collaboration with NASA, academia, Air Force Research Laboratory (AFRL), and GE. A decade of research provided enabling technology to both military and commercial engine programs that are pushing compression system aerodynamic loading and efficiency to new levels without incurring a reduction in efficiency. Industry now believes that tip injection

This material is declared work of the U.S. Government and is approved for public release; distribution is unlimited. 
cannot only be used to avoid stall, but also can be used as an alternative to variable geometry and to control stage matching in high speed compressors.

\subsection{NASA COLLABORATIONS WITH OTHER GOVERNMENT AGENCIES}

There are many examples of NASA collaborating with other government agencies such as DoE, DoD, and FAA. Though each government agency has a distinctive mission and objective, a given technology could have multiple uses; thereby allowing government agencies to combine resources and capabilities to advance the technology much further than either agency could accomplish in isolation. NASA is uniquely positioned to work with DoD and industry on proprietary and export control technologies; thereby enabling NASA to understand the needs of civilian and military aviation and to form collaborations that provide technologies that are beneficial to the entire community. Specific to turbomachinery and turbine engine applications, we will discuss two very different collaborations: 1) NASA collaboration with the Department of Defense on turbine-based combined cycle applications related to access to space and 2) NASA collaboration with the US Army on technologies to enable future rotorcraft missions requiring heavy vertical lift and efficient long range cruise.

\subsection{Turbine Based Combined Cycle Propulsion for Access to} Space - pushing the turbine engine design envelope.

NASA's Aeronautics Hypersonics Project is investigating turbine-based propulsion systems to develop technologies to enable airbreathing propulsion systems for the first stage of a two-stage-to-orbit vehicle for access to space. Refer to [56 and 57] for additional information. Turbine-based combined cycle (TBCC) propulsion provides the potential for aircraft-like, space-launch operations that may significantly reduce launch costs and improve safety due to the following characteristics:

1. Turbine-based propulsion systems exhibit significant specific impulse $\left(\mathrm{I}_{\mathrm{sp}}\right)$ improvements over rocket-based propulsion systems in the subsonic takeoff and return mission segments - see Figure 21. (Note for turbine engines $\mathrm{I}_{\mathrm{sp}}(\mathrm{sec})=3600(\mathrm{sec}) /$ specific fuel consumption.)

2. Turbine-based systems mitigate mission risk by providing operational flexibility for all-weather launch, take-off and landing cross-range, and powered landing and abort scenarios.

3. Turbine engines afford dual-use capability, adequately serving low-speed accelerator missions as well as longrange super-cruise missions.

4. Performance growth margin for TBCC engines can be inherently designed for the system, yielding a robust propulsion package to changes in mission requirements.

Two considerations for TBCC staging Mach number were investigated. One approach was to accelerate the turbine engine to Mach $4+$ in the first stage with the second stage as either all rocket or a Rocket Based Combined Cycle (scramjet + rocket).
The second approach was staging at Mach 7-10 with the first stage being a TBCC system with a turbine and scramjet integrated in an over-under configuration, as shown in Figure 22, followed by an all rocket second stage.

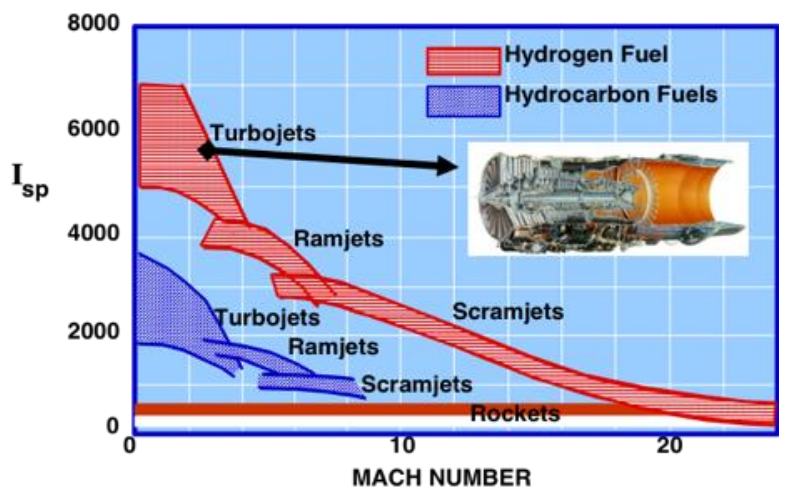

Figure 21. Airbreathing propulsion significantly increases propulsion efficiency. Vehicle Mach number vs. Specific Impulse, $\mathrm{I}_{\mathrm{sp}}=$ thrust/pound sec of propellant (fuel) flow. From [56].

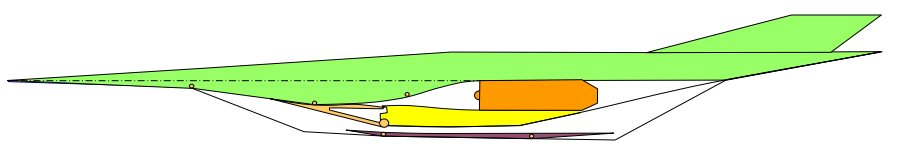

Figure 22. Schematic (not-to-scale) of dual mode inlet for the over-under TBCC first stage with a low speed inlet for the turbine (upper flowpath) and high speed inlet for the scramjet (lower flow path). Note hinged locations to regulate flow between low and high speed inlets during mode transition from low speed turbine operation to high speed scramjet operation. Presented at the NASA Fundamental Aero Program Oct 2008 and from [56].

5.1.1 Staging at Mach 7-10. The most critical enabling technologies for a reusable launch vehicle with an airbreathing TBCC first stage propulsion system and stage separation at Mach number greater than 7 were: 1) Mode transition from the low speed propulsion system (turbine engine) to the high speed propulsion system (scramjet), 2) high Mach turbine engine development, 3) transonic aero-propulsion performance, 4) lowMach-Number Dual-Mode Ram-to-Scramjet (DMRJ) operation, 5) innovative 3-D flow path concepts and 6) innovative Turbine Based Combined Cycle integration. To address several of these key challenges to enable TBCC capability, NASA developed a large-scale model of a fully integrated TBCC propulsion system with flow path sizing consistent with previous NASA and DoD Hypersonic experimental flight test programs that would be tested in the NASA-GRC 10'x10' Facility - see Figure 22. The ultimate goal of testing this Turbine-Based-Combined-Cycle (TBCC) large scale model was to address key hypersonic combine-cycle-engine issues: (1) the operating constraints of a Mach 3-7 combustor (specific to the TBCC), (2) dual integrated inlet operability and performance issues (i.e. unstart constraints, distortion constraints, bleed requirements and controls 
characterization, and operability margins), (3) mode-transition constraints imposed by the turbine and the ramjet/scramjet flow paths (imposed variable geometry requirements), (4) turbine engine transients (and associated time scales) during transition, and (5) high-altitude turbine engine re-light. The model will be tested in multiple test entries to develop a unique TBCC database to assess SOA design and analysis capabilities to predict performance, operability and integration / interaction issues of wide Mach range air breathing propulsion systems. To date, the dual integrated inlet has been designed and fabricated [58] and controlled inlet mode transition has been demonstrated with the turbine and scramjet engines being simulated by mass flow plugs. The next steps are to test the system with the turbine engine installed and a simulated scramjet, followed by a system test with both turbine and DMRJ installed.

5.1.2 Staging at Mach 4+. TBCC propulsion for hypersonic applications requires high Mach turbine engines to accelerate the vehicle to scramjet takeover speeds. Major challenges are to develop a turbine accelerator with Mach 4+ capability and to develop a scramjet with a low ignition speed $(\mathrm{M}<4)$ to enable transition from the low speed to high speed propulsion system. Staging at Mach $4+$ has the following advantages: 1) the integration issues and multiple fuels required for TBCC staging at Mach 7-10 are largely simplified, 2) the complexity of mode transition discussed above is replaced with stage separation, 3) the turbine engine is not cocooned, but rather continuously operates from take-off to subsonic cruise back to launch site, 4) the aero-heating inherent to hypersonic flight is avoided on the first stage; thereby allowing the vehicle and the high Mach 4+ turbine to require only existing materials, and 5) a high Mach 4+ turbine would have multiple uses for other applications.

Studies performed under NASA's Next Generation Launch Technology Program and the NASP High Speed Propulsion Assessment (HiSPA) program indicated a variable cycle turbofan/ramjet was the best configuration to satisfy access-tospace mission requirements for the first stage of a two-stage-toorbit system because this configuration maximizes the engine thrust-to-weight ratio while minimizing the frontal area [59]. To this end, NASA, AFRL, and GE teamed to design a variable cycle engine for an aircraft launch vehicle with Mach 4+ capability for access to space [60 and 61]. The flight envelope of a Mach 4+ like space launch vehicle operating from runway takeoff with continuous acceleration through transition from turbofan to ramjet operation requires a turbofan engine with a wide operating range capability - see Figure 23.

Critical to enabling the wide operating range of a Mach 4+ variable cycle turbofan ramjet required the development of a unique fan stage design. The fan stage must be capable of multipoint operation to provide high pressure ratio and efficiency at takeoff through the mid-range of engine operation, while avoiding stall and minimizing losses at the higher flight Mach numbers. To mitigate the risk of meeting the unique design requirements for the fan stage, NASA and GE teamed to design and build a $57 \%$ engine scaled fan stage to be tested in NASA's transonic compressor facility. The goals of this test were to assess the aerodynamic and aeromechanic performance and operability characteristics of the fan stage over its required range of operation from $15 \%$ to $100 \%$ fan corrected speed. The objectives of this research activity were to assess and document the capability of state-of-the art design and analysis tools (validated for subsonic flight vehicles) and to design and predict the performance and operability of an advanced fan stage designed to meet the requirements for the first stage of a twostage-to-orbit hypersonic vehicle (i.e. necessitating a wide multipoint operating range). These design and analysis tools are still relevant because the inlet has diffused the fan axial Mach number to subsonic, however the wide operating range and advanced configurations required for a Mach $4+$ vehicle result in using these tools beyond the operating ranges over which they were validated. The ultimate goal is to have confidence in the tools to design and analyze these advanced TBCC configurations in order to meet future mission requirements.

\section{RTA-1 / GE57 : Variable Cycle Engine Operation}
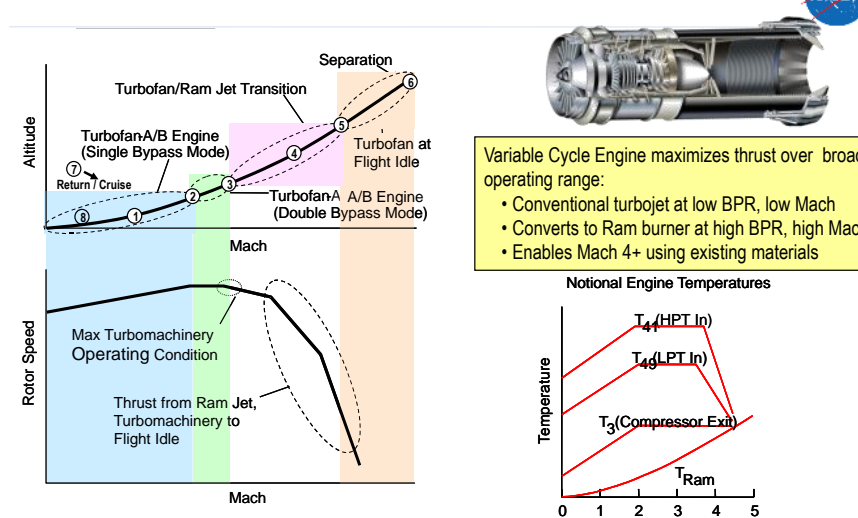

Variable Cycle Engine maximizes thrust over broad operating range:

- Conventional turbojet at low BPR, low Mach - Converts to Ram burner at high BPR, high Mach - Enables Mach 4+ using existing materials Notional Engine Temperatures

High Mach Turbine Engines Challenges Augmented by Wider Operating Range and excess Temperatures relative to SOA Engines

Figure 23. Operating modes of a Mach 4 turbofan ramjet from take-off with maximum acceleration to maximum temperature conditions through transition to double bypass-mode to separation at turbofan flight idle. From [60].

5.1.3 Fan Stage Design. An overview of the fan stage design requirements and traceability to a Mach 4 TBCC engine propulsion system is provided in References [61-63], where it is shown that the fan stage is a critical enabling component for the Mach 4 TBCC engine. The fan stage flow-path and components shown in Figure 24 are a 22 inch diameter scaled simulation of the engine ( 38 inch diameter) fan stage and includes the fan rotor, outlet guide vane (OGV), and splitter flow-path including the engine frame struts. To enable the wide operating range of a Mach 4+ capable engine required the development of a unique fan stage design for multi-point operation to accommodate variations in bypass ratio (factor of 10X), fan rotor speed (factor of 7X), inlet mass flow ( factor of 3.5X), inlet pressure (factor of $8 \mathrm{X}$ ), and inlet temperature (factor of $3 \mathrm{X}$ ). Herein, bypass ratio 
is defined as the ratio of mass flow in the bypass duct to that in the core duct. See Figure 24.

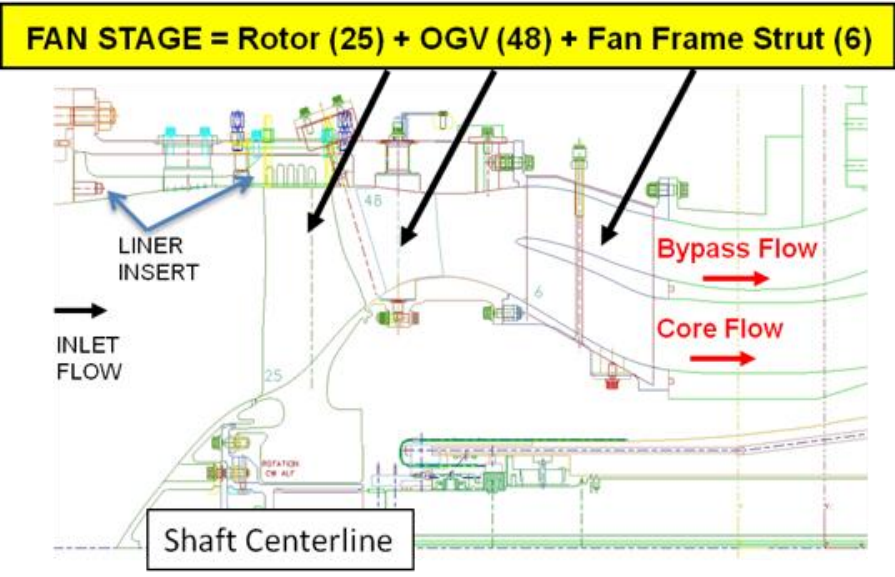

Figure 24. Fan stage components and flow path of the Mach 4+ turbofan ramjet from Figure 23. From [65].

These large variations of the inlet conditions and rotational speed introduced the following aerodynamic technical challenges to the fan stage design:

1. Stall free operation of the fan stage from $15 \%-110 \%$ rotor design speed (corrected).

2. Minimize the pressure losses through the fan rotor and OGV especially at the very high bypass ratios where the fan stage is at or approaching windmill conditions.

3. Avoid choking and provide clean and stable flow in the bypass and core ducts throughout the 10x range of bypass ratio.

4. Deliver the required inlet conditions to the downstream engine components (ramjet and core compressor), from takeoff through transonic and to ramjet operation.

These technical challenges were augmented by the requirement to maintain traceability to the reference TBCC vehicle which resulted in 1) a fan stage design without inlet guide vanes; thereby, making it more difficult to maintain performance and operability over the wide operating range, and 2) a bypass duct arrangement that must maintain a diameter consistent with scaleup to the reference vehicle, yet not be so small as to incur large pressure losses or potential flow choking resulting from high Mach numbers in the duct. Overall fan stage performance and operability therefore requires major consideration, as competing goals at different operating points become major drivers in the design. The details of the mechanical design and aeromechanic test data are found in [62 and 63], respectively.

The fan stage was designed by GE following their standard design practice, with close collaboration from NASA engineers providing multistage CFD analysis in support of the design with emphasis on operability and performance at off-design conditions. The fan rotor was designed to produce a high pressure ratio (2.5) at lower flight Mach numbers while maintaining adequate stall margin $(>10 \%)$ across a wide range of operating conditions. In order to deliver the required performance, an advanced technology, forward swept fan rotor design [62-64], was employed. The fan stage design operating line (as determined by GE's cycle code to meet mission requirements) is depicted by the black line connecting the black circles in Figure 25. CFD simulations were used to update the fan stage performance maps in the engine cycle deck. Single blade row CFD analyses were run, using GE's inhouse code, along the operating line at $100 \%, 90 \%, 80 \%, 50 \%, 37 \%, 20 \%$ and $15 \%$ of design speed, as well as near stall at $100 \%$ and $80 \%$ speed. Multi-stage CFD analyses, utilizing NASA's APNASA code, were also conducted at select operating conditions $(100 \%$, $50 \%$, and $37 \%$ of design speed. These simulations predicted that the fan stage should be capable of matching the design intent across the operating range. In order to ensure adequate stall margin over the operating range, the fan stage test article provided the flexibility to incorporate various casing treatments over the fan rotor by installing a liner insert as depicted in Figure 24.

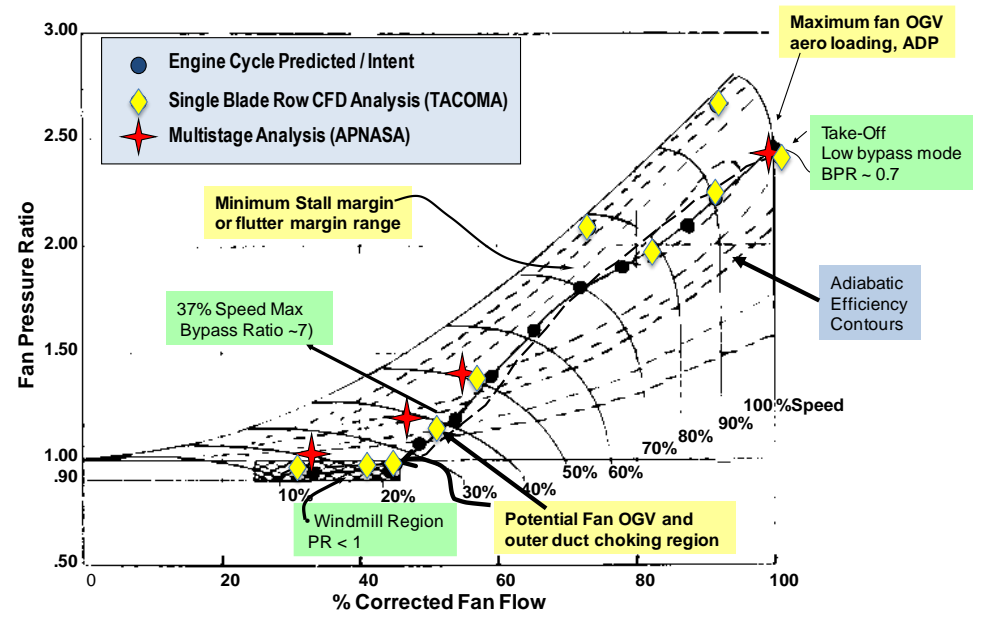

Figure 25. Mach 4+ Turbofan Ramjet engine Fan stage operating map - design operating line indicated by black circles. From [65].

The fan stage was tested in the NASA W8 Single Stage Compressor facility, which was modified to enable independent throttling of the bypass and core flow ducts to map the compressor over the wide range of operating conditions. Aerodynamic fan stage performance characteristics at $15 \%$, $25 \%, 37 \%, 50 \%, 60 \%, 70 \%, 80 \%, 85 \%, 90 \%, 95 \%$, and $100 \%$ of rotor design speed, encompassing a bypass ratio swing from 0.7 to 7 , were acquired. These experimental results of the fan stage characteristics were acquired for three different fan rotor casing configurations corresponding to 1) smooth wall at nominal fan tip clearance, 2) circumferentially grooved casing at nominal tip clearance, and 3) circumferentially grooved casing with a more open clearance. The liner influenced the stage performance and operability for fan speeds greater than $70 \%$ speed, but no influence was measured below $70 \%$ speed where 
the tip clearance was larger and the shock strength reduced relative to design speed. At $90-100 \%$ speeds, the relief provided by the grooves to enable lower flow rates and more stability margin at near stall operation was offset by increased blockage (resulting in a reduction of the maximum flow) and a lower efficiency at higher flow rates. The experimental data and NASA CFD predictions agreed favorably with the design intent in terms of pressure ratio, efficiency, and mass flow along the operating line. - see Figure 26. It was shown [65 and 66] that the OGV loading and losses were sensitive to the OGV setting angle and that a variable $\mathrm{OGV}$ was required to match the swings in incidence and inlet Mach number over the wide operating range. Furthermore, it was shown that the OGV (not the fan) is the airfoil most sensitive to variations in stage performance over this wide operating range. The distortion measured from the TBBC large scale inlet described in References [56-58] and depicted in Figure 22 was simulated with distortion screens at the inlet of the fan stage. The data were used to evaluate the impact of distortion on the fan stage performance and operability in order to assess the ability of the SOA tools.

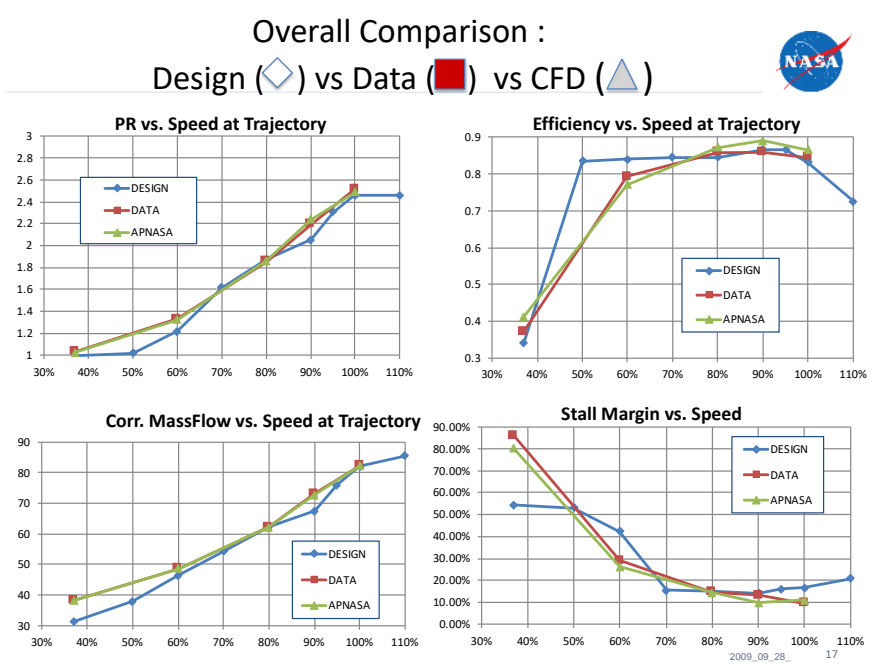

Figure 26. Comparison of experimental data and NASA CFD to design intent along the operating line (labelled trajectory) from Figure 25.

\section{WHY NASA? NASA ability to explore high-risk high- benefit technologies that industry would not pursue on its own. In addition, NASA collaborations involve NASA CFD codes and faclities thereby; providing the capability to share results with the community that otherwise would not have been shared.}

The data and hardware design were shared with DARPA, U.S. Air Force, U.S. Navy, and appropriate industry partners (inclusive of Aerojet, Lockheed Martin, SPIRITECH, TechLand, Williams International, Rolls-Royce, Pratt \& Whitney, General Electric Aviation, ATK, and others) to continue the development of these complex hypersonic propulsion systems. NASA and industry design and analysis tools were pushed well beyond their experience base and the lessons learned will be helpful for future subsonic, supersonic, and hypersonic vehicles in which the propulsion system is more highly integrated with the vehicle. It is also clear that industry alone would not have invested in developing a turbine engine for access to space applications without NASA and DoD endorsement.

Perhaps more important to the civil aircraft engine community is the contributions this research made to advancing and validating the design and analysis tools beyond the conventional subsonic aircraft engine design trade space. In the future collaboration section near the end of this paper, we will discuss advanced propulsion system architectures requiring a variable cycle engine which is highly integrated with the vehicle and subjected to extreme levels of inlet distortion. The lessons learned in the engine design for access to space discussed above, will be beneficial to conquer the barriers of the future civil aviation vehicles.

\subsection{Variable Speed Power Turbine (VSPT) - enabling future vertical lift propulsion requirements.}

NASA and the U.S. Army combined resources and collaborated to develop and demonstrate a Variable Speed Power Turbine (VSPT) with a 50\% improvement in operational capability to enable the demands of future rotorcraft mission requirements. NASA's Revolutionary Vertical Lift Technology (RVLT) project was developing technologies to enable a Large Civil Tiltrotor (LCTR) with a payload of 90 passengers and greater than $1000 \mathrm{~nm}$ range with a cruise speed of 300 knots at an altitude of 28,000-30,000 ft. At the same time, the U.S. Army was developing the Advanced Variable Speed Power Turbine (AVSPOT) program to focus on the aerodynamic challenges associated with delivering high shaft power at a wide range of Power Turbine speeds in a medium/large engine class $(2,000$ to 10,000 SHP). Though NASA and the U.S. Army had different missions, there was a mutual interest in high efficiency, wide operating speed range, variable speed power turbine technology. Therefore, NASA and U.S. Army evenly split the government cost of awarded cost-share contracts to P\&W and GE to develop and demonstrate a VSPT with both: 1) Efficiency of $92 \%$ or better at the Maximum Rated Power (MRP) condition corresponding to operation at sea-level conditions to hover at $100 \%$ main rotor speed and 2) Efficiency of $90 \%$ or better at the Maximum Continuous Power (MCP) corresponding to cruise at $25,000 \mathrm{ft}$. at Mach 0.5 at $54 \%$ main rotor speed. Refer to Figure 27 which compares the State-of-the-Art (SOA) to the VSPT and AVSPOT performance goals. Note that the overall benefit of achieving high efficiency over the wide operating range is significant enough to tolerate a slight reduction in efficiency (relative to SOA power turbines) at the MRP or $100 \%$ main rotor speed condition.

Independent system studies performed by NASA and Boeing showed that advanced turboshaft engines with VSPT would have the benefits of a 13\% lower Take-off Gross Weight (TOGW) and a 25-28\% lower fuel burn for the NASA RVLT LCTR mission [67-72]. At takeoff, the LCTR main rotors and 
the VSPTs operate at $100 \%$ speed, while at cruise the rotors tilt forward and the VSPTs are slowed to 54\% speed to enable higher efficiency. high speed forward flight cruise. The LCTR engine requirements were established with the NASA engine performance group [73]. The cruise and takeoff VSPT enthalpy extraction levels differ by only 8 to $10 \%$. As the shaft is slowed from $100 \%$ to $54 \%$ of the takeoff speed, the turbine work factor $\left(\Delta \mathrm{h}_{\mathrm{t}} / \mathrm{U}_{\text {tip }}{ }^{2}\right)$ is increased by a factor of 3.4. The corrected flows (or Mach numbers) do not change significantly, and therefore the flow coefficient essentially doubles between the takeoff (100\%) and cruise $(54 \%)$ operating conditions. The nearly constant corrected flow rates and the $40 \%$ corrected speed change lead to incidence angle variations of $40^{\circ}$ to $60^{\circ}$ in all turbine blade and vane rows downstream of the first vane, including any required exit guide vane row. The aerodynamic challenges include attainment of high turbine efficiency with incidence variations in all blade rows associated with the shaft speed change, combined with operation at low Reynolds numbers with attendant sensitivity to transitional flow. The loss levels in the transitional flow fields of low-pressure turbines (LPTs) operating at cruise altitudes (with $R e<100 \mathrm{k}$ ) are strongly affected by wake-induced unsteadiness as well. The mechanical challenges are associated with the required avoidance or management of responsive shaft, blade, and casing modes at critical speeds within the operational speed range of the VSPT shaft. More details on the VSPT challenges are discussed in References [74-76].

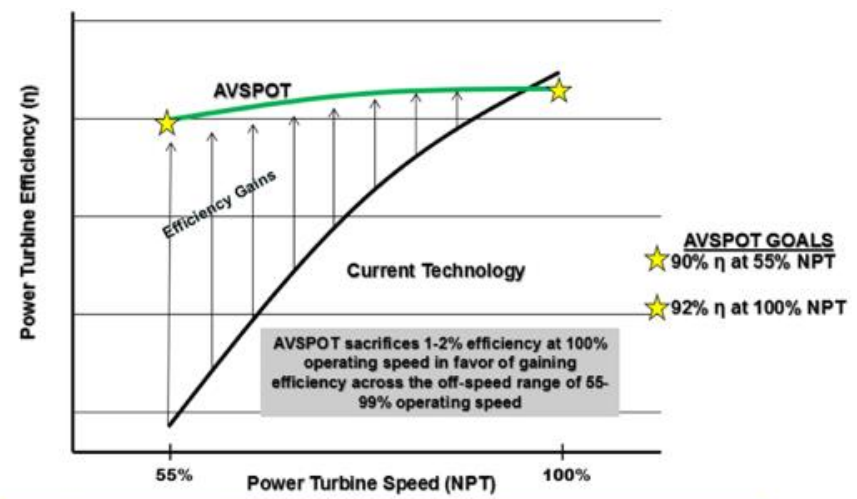

AVSPOT seeks to improve power turbine efficiency over a wide operating range versus conventional power turbine design

Figure 27. Variable Speed Power Turbine (VSPT) performance goals relative to current technology. From [87].

NASA awarded VSPT study contracts to Rolls-Royce and Williams International to define a notional VSPT. The contractor reports can be found in References [77] and [78]. The RollsRoyce VSPT concept was selected and the third stage of their VSPT was used to design a non-proprietary incidence tolerant blade design which was tested in the NASA CW-22 facility and in the University of North Dakota (UND) turbine cascade facilities. NASA VSPT blade cascade testing at high and low inlet turbulence levels over a large range of Mach numbers, Reynolds numbers, and incidence provided a benchmark data base to validate the ability of CFD analysis codes to predict the
VSPT losses over the entire flight operating envelope. A sample of the test results are provided in Figures 28 and 29. Additional details of the experiment(s) and their results are documented in References [79-85]. NASA used these test results to validate the ability of models to predict flow separation and laminar-toturbulent flow transition. The data at low and high inlet turbulence provides a unique opportunity to develop LES methods in a step-wise manner. The low inlet turbulence data enables LES without the necessity to model the inlet turbulence via a sub-grid model References [85 and 86]. These test results were provided to $\mathrm{P} \& \mathrm{~W}$ and GE to assist them with their VSPT designs.

P\&W and GE independently developed notional engines to define the design requirements for their power turbines to meet the NASA/Army performance requirements under the Army's Advanced Variable Speed Power Turbine (AVSPOT) program. Based on their notional engine VSPT component test rigs were designed, fabricated, and tested to demonstrate that their design would meet the performance requirements. The nearly fullscale, multi-stage VSPT component rigs were tested and met or exceeded the efficiency goals of the design. These results were especially satisfying because the goals were very aggressive (Figure 1) and they were achieved without employing a variable turbine geometry. CFD was integrally used in the VSPT design process. Pratt \& Whitney's and GE's post-test analysis of the detailed rig data indicated that their CFD codes had accurately predicted the radial distribution of the key flow field parameters, the vane pressure distributions, and the overall performance over the wide operating range. In addition, NASA independently performed CFD analysis using TURBO [88] and the ADS Code LEO [89] for the P\&W VSPT design. As shown in Figure 30, the NASA CFD predicted the overall performance of the VSPT at $55 \%$ speed and $100 \%$ speed in reasonable agreement with the $\mathrm{P} \& \mathrm{~W}$ test results. Additional details of these results are provided in reference [87].

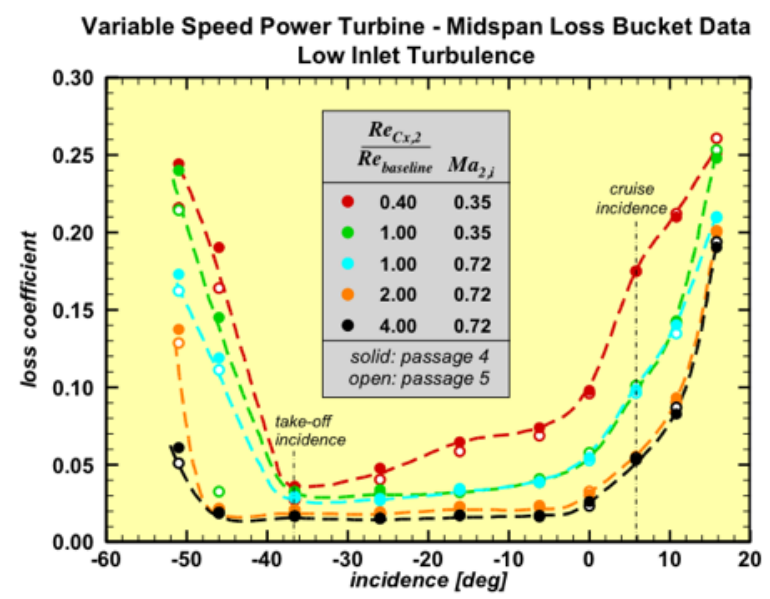

Figure 28. VSPT Blade Loss Coefficient versus Incidence for various Reynolds and Mach numbers - Low Inlet Turbulence. From [87]. 


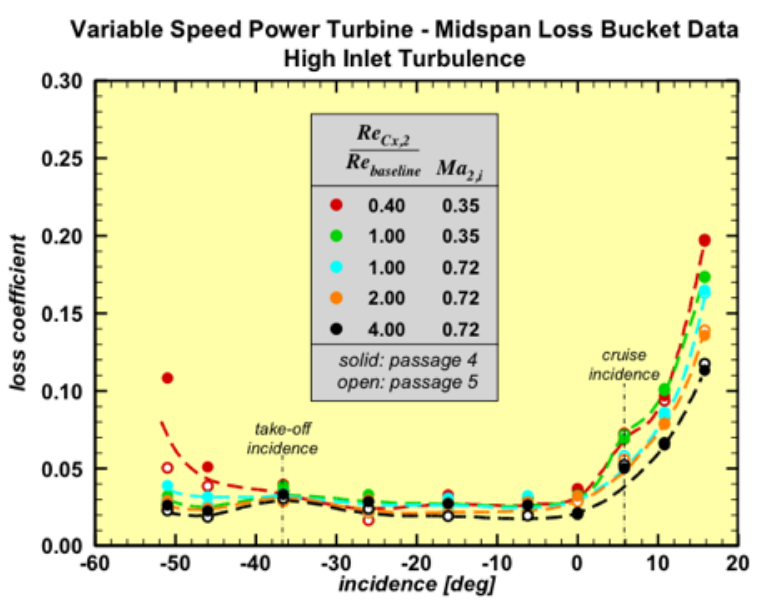

Figure 29. VSPT Blade Loss Coefficient versus Incidence for various Reynolds and Mach numbers - High Inlet Turbulence. From [87].

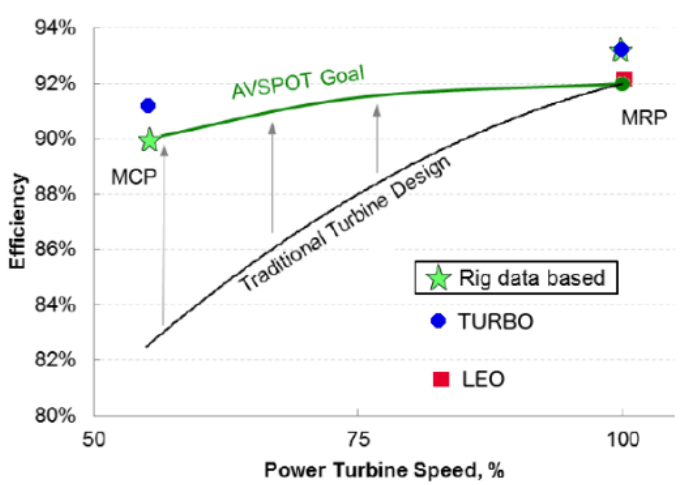

Figure 30. NASA TURBO and LEO CFD results compared to $P \& W$ VSPT test rig results and the AVSPOT program goals. From [87].

\section{WHY NASA? NASA resourcefulness to identify potential high-risk but high-benefit technologies that industry would not pursue on its own, and leverage other government agencies and form collaborative teams with NASA leading the technology development.}

NASA conceived and developed the idea to pursue incident tolerant blade design as an alternative to a variable speed transmission to enable efficient vertical lift and efficient cruise for rotorcraft missions. NASA conducted system studies internally and sought confirmation by contracting Boeing to independently conduct studies to assess the benefit and feasibility of a VSPT. NASA sought collaboration with the U.S. Army to demonstrate the technology and NASA provided a benchmark dataset to aid industry in developing their proprietary designs. Successful completion of these VSPT component rig tests raised the VSPT Technology Readiness Level (TRL) from TRL 2 to TRL 5 and demonstrated the potential of the VSPT concept as a viable approach to improve engine efficiency over a wide range of operating conditions. Furthermore, the success of this VSPT design and demonstration has led to a funded Army DoD 6.3 Alternative Concept Engine (ACE) program to build and demonstrate an engine with a variable speed power turbine. An agreement was awarded to the Advanced Turbine Engine Company and announced in 2016 [90]. Upon successful completion of the ACE 6.3 effort, variable speed power turbine technology will achieve a TRL 6 and be adequately matured to allow for potential fielding in future rotorcraft. In summary, this significant advancement in technology to enable future rotorcraft for civil aviation and U.S. Army applications was achieved due to contributions from NASA, U.S. Army, GE, P\&W, Rolls-Royce, Williams International, Boeing, and the Univ. of North Dakota. It is important to note that both GE and P\&W each provided significant cost share for this effort and NASA and the U.S. Army evenly split the government funding for the P\&W and GE contract awards.

\subsection{NASA COLLABORATIONS \& TECHNOLOGY DEMONSTRATIONS THAT ARE MAKING THEIR WAY IN TO FUTURE PRODUCTS}

NASA's Environmentally Responsible Aviation (ERA) Project focused on developing and demonstrating integrated systems technologies to TRL 4-6 by 2020 that enable reduced fuel burn, emissions, and noise for futuristic air vehicles. The specific goals aimed to simultaneously reduce fuel burn by $50 \%$, reduce Landing and Take-off Oxides of Nitrogen emissions by $75 \%$ relative to the CAEP 6 guidelines, and reduce cumulative noise by $42 \mathrm{~dB}$ relative to the ICAO Stage 4 guidelines. See Figure 31. These goals apply to the integrated vehicle and propulsion system and are based on a reference mission of 3000 $\mathrm{nm}$ flight of a Boeing 777-200 with GE90 engines. It is interesting to note that ERA was essentially a scaled down version of the 1975 Aircraft Energy Efficiency (ACEE) Program discussed earlier in the background section. ERA focused on similar technical challenges and the approach was similar in that to reduce specific fuel consumption it is best to improve both the core thermal efficiency and the propulsive efficiency (refer to Figure 1). Unique to ERA, NASA required substantial industry cost share and was constrained to a 6 year period of performance. See References [91-93] for more background on the ERA project. This section of the paper will highlight the propulsion elements of the ERA technology portfolio inclusive of the core compressor, propulsor, and combustor technology demonstrations.

\begin{tabular}{|c|c|c|c|}
\hline \multirow{2}{*}{$\begin{array}{l}\text { TECHNOLOGY } \\
\text { BENEFITS" }\end{array}$} & \multicolumn{3}{|c|}{$\begin{array}{c}\text { TECHNOLOGY GENERATIONS } \\
\text { (Technology Readiness Level }=4-6 \text { ) }\end{array}$} \\
\hline & $\mathrm{N}+1$ (2015) & $N+2\left(2020^{\circ 1}\right)$ & $\mathrm{N}+3(2025)$ \\
\hline $\begin{array}{c}\text { Noise } \\
\text { (cum margin rel. to Stage 4) }\end{array}$ & $.32 \mathrm{~dB}$ & $-42 \mathrm{~dB}$ & $.52 \mathrm{~dB}$ \\
\hline $\begin{array}{l}\text { LTO NOx Emissions } \\
\text { (rel. to CAEP 6) }\end{array}$ & $-60 \%$ & $.75 \%$ & $-80 \%$ \\
\hline $\begin{array}{l}\text { Cruise NOx Emissions } \\
\text { (rel. to } 2005 \text { best in class) }\end{array}$ & $.55 \%$ & $-70 \%$ & $-80 \%$ \\
\hline $\begin{array}{l}\text { Aircraft FueV/Energy Consumption }{ }^{2} \\
\text { (rel. to } 2005 \text { best in class) }\end{array}$ & $.33 \%$ & $.50 \%$ & $-60 \%$ \\
\hline
\end{tabular}

Figure 31. NASA subsonic transport system level metrics. 


\subsection{NASA ERA Core Compressor Technology Development.}

The ERA core compressor activity was a collaboration between NASA and GE Aviation. To achieve the system goals, the goal of the ERA highly loaded compressor activity was to increase efficiency and to increase pressure rise by $30 \%$ relative to the ERA baseline engine (GE90 engine on the 777-200) in order to achieve a $2.5 \%$ reduction in engine specific fuel consumption. Two test and analysis campaigns explored the design space to improve the compressor Overall Pressure Ratio (OPR) and optimize the blade loading and efficiency without negatively impacting weight, length, diameter, or operability. The first test campaign (NASA ERA Phase 1) investigated the front two stages of a legacy high-pressure ratio six-stage core compressor to determine what limits blade loading. The second test campaign (NASA ERA Phase 2) focused on two builds of the front stages of a new compressor design. A pictorial view of the design space explored is found in Figure 32. The dashed line represents compressor trade space state of the art (SOA) for blade loading (represented as the change in enthalpy divided by the square of the rotor tip rotational speed) and efficiency. As shown, the higher blade loading, the more difficult it is to achieve high efficiency. Any compressor with a design point above the dashed line would represent a design that was better than the SOA.

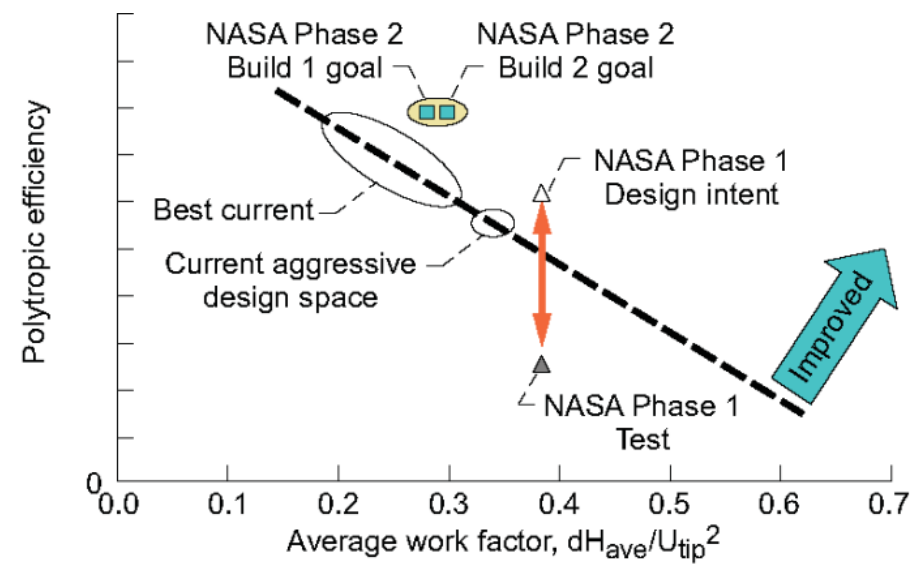

Figure 32. Compressor design space for ERA Phase 1 and Phase 2 relative to the state-of-the-art best current practices as indicated by the dashed line, representing the change in enthalpy $\mathrm{dH}_{\text {ave }}$ divided by the square of the rotor tip rotational speed. From [93].

In ERA Phase 1, a legacy high-OPR compressor design that fell short of the efficiency design goals was investigated. The high losses were attributed to the front two stages of this highly loaded six-stage compressor design. The front two stages are transonic across the span, so their performance is very sensitive to variations in the effective flow area. Those area variations can affect the location and strength of the passage shocks and further impact flow separations and/or low momentum and loss regions due to the shock and/or blade row interactions. Figure 33 shows the results of an unsteady CFD analysis by Gorrell [94] of the front two stages of the compressor and it highlights the entropy (loss) regions for the transonic compressor flow field. NASA tested the first stage in isolation followed by the two-stage configuration in the NASA W7 multi-stage compressor facility to evaluate the performance and losses in each stage. For both 1 - and 2-stage configurations, detailed data were taken at $97 \%$ design speed, acquiring data from leading-edge (LE) instrumentation, wall statics, over-the-rotor high frequency response Kulite pressure sensors, and traversing probes. The results indicated that Stage 2 was choking at a mass flow rate that prevented Stage 1 from reaching its peak efficiency point, leading to a stage mismatch issue. The mismatch was thought to be due to losses in the first stage that were not predicted by design tools. Assessment of the Stator $1 \mathrm{LE}$ measurements in both test configurations revealed that the level of performance at this location was unaffected by the presence of the second stage. Therefore, the major source of unexplained loss resulted from the first stage of the compressor. For additional details and discussion of the CFD analysis and experimental test results refer to Celestina, et al. [95], Prahst et al [96] and Lurie et al [97].

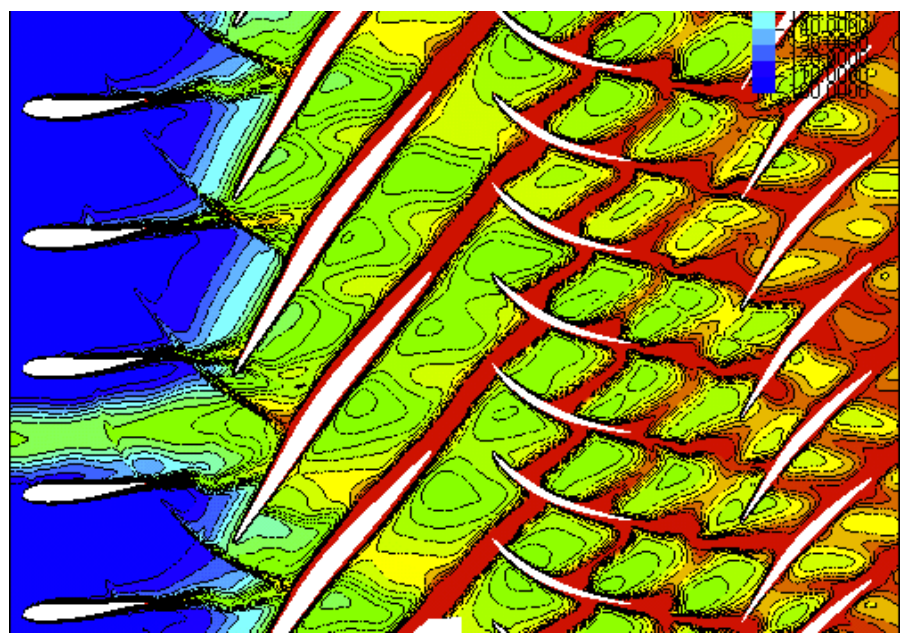

Figure 33. Shock and wake loss regions due to unsteady blade row Interactions (for the IGV + Rotor 1 + Stator 1 + Rotor 2) along the midspan stream surface of a highly loaded compressor identified by Entropy contours from Gorrell et al, 2005 [94].

ERA Phase 2 brought forward a completely new core compressor design strategy and leveraged lessons learned from the Phase 1 compressor design. The Phase 2 compressor was designed for increased efficiency and blade loading, relative to best current design as shown Figure 32. However, based on learnings from Phase 1, the blade-loading levels were increased relative to best current design but not to the higher levels of blade loading that were attempted in the Phase 1 design discussed previously. For ERA Phase 2, NASA tested the first three stages of a high-efficiency, high-OPR core compressor design in the same NASA facility as the Phase 1 testing. The Phase 2 compressor test campaign consisted of a Build 1 test and a Build 2 test in which the primary difference was that Build 2 was designed to achieve higher compressor blade loading (pressure 
rise per stage) at the same efficiency levels of Build 1, as shown in Figure 32. The higher blade loading of Build 2 provided an overall system benefit because it allowed for the compressor bleed locations to be moved further upstream, thereby reducing the compressor work required to provide the bleed flow. Extensive CFD simulations that have been conducted are not only in agreement with each other but are also in agreement with the design intent. Build 2 testing indicated the compressor met its design intent. These technology demonstrations contributed to GE's advanced core compressor development.

\subsection{NASA ERA Propulsor Technology Development Effort.}

The NASA ERA performance goals for the propulsor were a 9\% Reduction in TSFC and a 15 EPNdB cumulative noise reduction relative to the baseline engine. Advanced ultra-highbypass ratio propulsors are attractive to provide increased propulsive efficiency and reduced fan and jet noise to meet the ERA goals at the expense of increased nacelle weight and drag for ducted propulsors. Unducted open rotor systems optimize propulsive efficiency with ultimate bypass ratio and low fan pressure ratio but lack nacelle liners thereby resulting in less noise suppression than ducted systems. To address these challenges the approach was to study the trade space between fuel burn and noise reduction by assessing ducted and unducted propulsor systems.

\subsubsection{NASA ERA Ducted Ultra High Bypass (UHB)} Propulsor Technology Development Efforts. Aircraft engine noise and fuel burn reduction are directly correlated to fan size, fan pressure ratio, and fan bypass ratio. As the fan size increases, there is a corresponding drop in the fan pressure ratio and an increase in fan Bypass Ratio (BPR). At some point, as the fan size continues to increase, an optimum is reached between fan size and nacelle weight and drag. The larger, heavier nacelle produces more drag during flight, and overcomes the advantages of a larger fan. The addition of a gear to the fan drive system allows the low tip speed, low Fan Pressure Ratio (FPR) fan to be coupled to a smaller, more efficient, high speed core. This shifts the minimum fuel burn FPR to a lower value for geared turbofan as shown in Figure 34. However, note that the fan diameter is also increasing to produce an equivalent amount of thrust. For higher thrust class engines, the nacelle will become prohibitively large with high drag unless reduced length nacelles are also implemented [98]. These configuration changes are beneficial for fuel burn but potentially detrimental for acoustics. Therefore, to meet the ERA goals for fuel burn reduction and noise reduction, NASA collaborated with Pratt \& Whitney and the Federal Aviation Administration to develop and demonstrate an Integrated UHB fan with a low weight nacelle system and advanced noise reduction technologies.

For engines with large diameter fans and reduced length nacelles the internal surface area for acoustics liners is reduced and the effectiveness of the liners is also lowered due to the less optimal Length to Diameter (L/D) ratio of the bypass duct. To increase the acoustic treatment area in the propulsor the NASA ERA program developed two advanced liner concepts; over the rotor (OTR) and soft vanes (SV). The OTR concept is an acoustically designed casing treatment which is located over the rotor tip region. The details are not releasable as a patent is in process. The design intent is to absorb pressure fluctuations at the source before the sound can propagate to the far field. The SV concept uses cylindrical, folded passages in the fan exit guide vanes to absorb pressure fluctuations at their source. Both concepts are used to effectively increase the acoustically treated area within the propulsor. The OTR/SV concepts were tested in a legacy 1.5 pressure ratio fan, both in a rotor only configuration to analyze any performance impact [99] and in a flight nacelle configuration to measure the acoustic characteristics. The nacelle configuration is shown schematically in Figure 35 . The rotor-alone measurements showed a minimal and acceptable loss in efficiency due to the OTR treatment. The acoustic results from the flight nacelle showed a noise reduction for the SV concept of $1.5 \mathrm{~dB}$ but no noise reduction for the OTR concept. Manufacturing difficulties for the OTR concept and acoustic design limitations for the rotor tip flow field conditions are the likely causes of the inconclusive acoustic results for the concept.

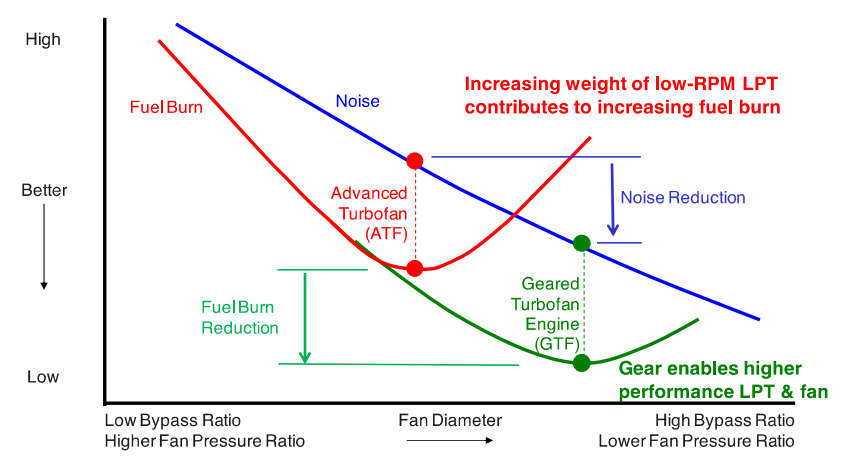

Figure 34. Fuel burn and noise characteristics of advanced turbofans and geared engines (from P\&W, 2015 [93].

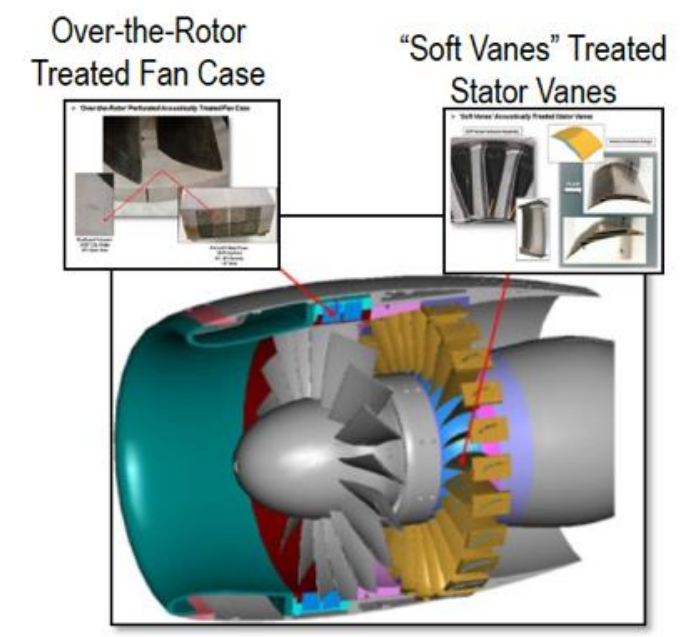

Figure 35. Over the rotor (OTR) and Soft Vane (SV) acoustic concepts in the legacy 1.5 Fan Pressure Ratio (FPR) fan model. From, [93]. 
The final wind tunnel test of the series, known as Rig 2, used a scale model version of the FAA CLEEN engine. The wind tunnel model contained many of the features of an engine such as a drooped inlet, pylon/bifurcation in the bypass duct, classed exit guide vanes and a non-axisymmetric bypass duct. A comprehensive data set was acquired to assess performance, operability, and acoustics; thereby validating the SOA design and analysis tools. A primary objective of the experiment was to compare model scale acoustic results to those of the upcoming full-scale ground engine test. NASA nor FAA would have been capable with their funding alone to complete this comprehensive series of test programs.

6.2.2 NASA ERA Unducted Propulsor Technology Development Efforts. Propulsion systems incorporating open rotors have the potential for game-changing reductions in fuel burn because of their low fan pressure ratio and thus increased propulsive efficiency. To meet the ERA goals for fuel burn reduction and noise reduction, NASA collaborated with General Electric Aviation and the Federal Aviation Administration to explore the design space for lower noise while maintaining the high propulsive efficiency from a counter-rotating open-rotor system. Candidate technologies for lower noise were investigated as well as installation effects such as pylon and fuselage integration. Advances in computational fluid dynamics over the last 20 years enable three-dimensional (3D) tailoring of blade shapes to minimize noise while still maintaining efficiency. These modeling advances increase the possibility of meeting both noise and efficiency goals simultaneously for the new generation of open-rotor designs.

During the test campaign six different blade sets or unique combinations of fore and aft blades were evaluated for their aerodynamic performance and acoustic characteristics. One of the blade sets, the Historical Baseline blade set, is representative of 1990s blade design. Aerodynamic and acoustic measurements of the Historical Baseline blade set were used as a benchmark dataset to improve modeling and simulation capabilities for open rotors. The other five blade sets represent modern designs that incorporate various $3 \mathrm{D}$ design features and other strategies to reduce the acoustic signature but maintain performance. The open-rotor test campaign is documented in References [100 and $101]$, and the following paragraphs provide a brief synopsis of the activity.

The open-rotor test program consisted of three phases: (1) takeoff and approach aerodynamics and acoustics, (2) diagnostics, and (3) cruise performance. For Phases 1 and 2 the Open Rotor Propulsion Rig (ORPR) was installed in the 9- by 15-Foot Low-Speed Wind Tunnel (9X15 LSWT) at GRC. The ORPR was completely refurbished for the current test entry and also underwent significant upgrades such as a new digital telemetry system for rotor force and strain gage monitoring. For the third phase of testing the rig was installed in the 8- by 6-Foot Supersonic Wind Tunnel (8X6 SWT) for cruise performance testing. NASA acquired a substantial amount of aerodynamic and acoustic data on a variety of blade geometries for an isolated configuration during the Phase 1 testing. Figure 36 [90] compares the fuel burn and noise levels of the GE36 (1980's open rotor) and turbofan engine to a modern open-rotor design. It is clear from Figure 36 that the modern open-rotor designs provide significant improvements in both fuel burn and noise relative to the 1980's GE36 UDF design; thereby making the open rotor a viable propulsor concept for the next generation of fuel-efficient aircraft.

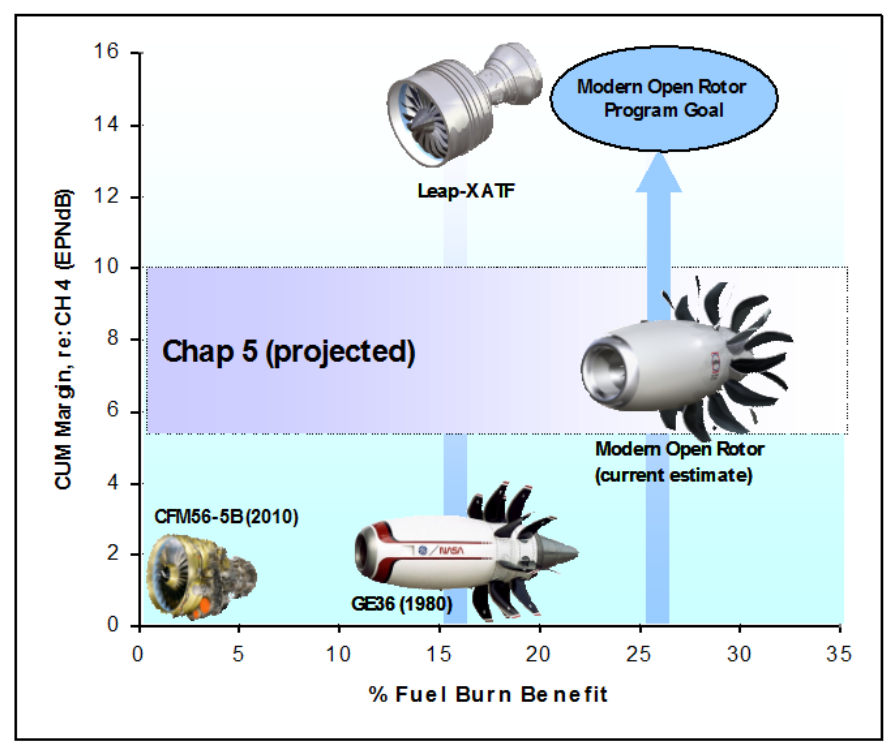

Figure 36. Modern open rotor designs provide greater than $25 \%$ reduction in fuel burn and about 8 EPNdB noise margin to International Civil Aviation Organization Chapter 4 standard (ICAO, 2008). From [92].

\subsubsection{NASA Evaluates Propulsor SFC versus Noise} Trade Space. In order to perform a direct comparison of an unducted open-rotor system to a high-BPR ducted propulsor, NASA leveraged the research reported above and designed a common aircraft platform to compare the tradeoff between fuel burn and noise reduction [102]. The NASA notional aircraft design was a modern 162-passenger airplane with rear fuselagemounted engines and with a cruising Mach number of 0.78 at $35,000 \mathrm{ft}$ and a mission range of 3250 nautical miles. A comparison of the fuel burn and noise for the open-rotor and ducted high-bypass propulsors are shown in Figure 37. The aircraft with the open-rotor propulsor provided an additional $9 \%$ reduction in fuel burn despite the increased weight of the engine and at the expense of an increase of $7 \mathrm{~dB}$ cum in noise relative to the ducted propulsor for this notional aircraft size and mission.

\subsection{NASA ERA Advanced Combustor Technology Development Effort.}

The NASA ERA performance goal for the combustor was a $75 \%$ reduction in LTO NOx relative to the CAEP 6 standard. NASA ERA collaborated with General Electric (GE) Aviation and Pratt \& Whitney (P\&W) in a cost share agreement to develop the new lean burn concepts and demonstrate these concepts in a 
sector rig test that simulates the pressures and temperatures of a relevant high OPR (>50) engine environment. The NASA Glenn Research Center (GRC) Advanced Subsonic Combustor Rig (ASCR) facility was upgraded to provide combustor entrance conditions up to a pressure of 900 psia and temperature up to $1300 \mathrm{~F}$ to simulate an OPR 50 engine in order to perform the combustor sector rig testing. These sector test results are presented in reference [92].

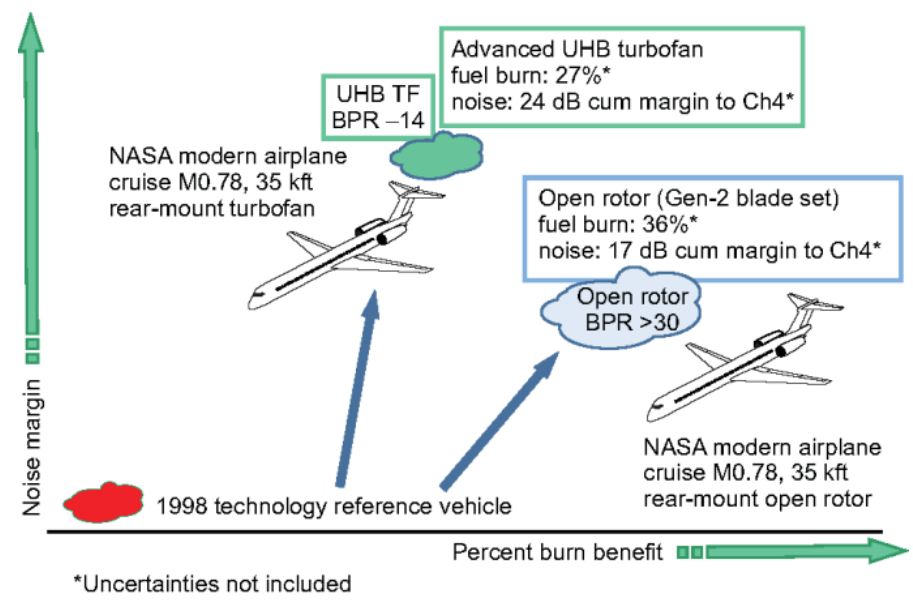

Figure 37. Comparison of advanced turbofan and open rotor on common aircraft platform (From Hendricks, E. S., J. J. Berton, W. J. Haller, M. T. Tong, and M. D. Guynn. 2013. From [102].

GE Aviation designed and tested advanced lean burn combustor concepts, which extended from the Twin Annular Premixing Swirler (TAPS) developed under GE and NASA sponsored Advanced Subsonic Technology (AST) and Ultra Efficient Engine Technology (UEET) programs. More recently, the TAPS combustor was further developed for application in the new GEnx-1B and GEnx-2B engines that power the Boeing 787 and 747-8 wide-body aircraft, respectively. The TAPS design consisted of independently controlled, swirl stabilized, annular flames for low power (pilot) and high power (main) operation. The central pilot flame provided good low power operability and low $\mathrm{CO}$ and $\mathrm{HC}$ emissions. The main flame is concentric with the pilot flame and was designed to produce low NOx emissions during high power operation. The combustion system incorporated advanced liner materials that benefitted both durability and emissions by decreasing cooling air requirements and enabling a higher fraction of combustion air in the main mixer for lower NOx emissions. Several advanced TAPS injector concepts were designed and tested in a flame tube configuration to evaluate emissions, combustion dynamics, and auto ignition margin up to full operating conditions. Based on testing and analysis results an injector design was selected and was incorporated into an advanced 5-cup sector rig at NASA's ASCR facility. The ASCR facility provides the capability to obtain data over the entire flight envelop including high power operation for the inlet conditions required to calculate the ICAO LTO NOx emissions level for engines with an overall pressure ratio of 50:1. The GE sector test results [92] indicated that the GE combustor concept had the potential to meet the ERA goals.

Pratt \& Whitney (P\&W) concepts included lean-staged multi-point designs, radially staged swirlers, rich-quench-lean (RQL) combustors, and axially staged combustors. The simplicity, operability, durability, and excellent emissions of the RQL family of combustors have led to the continued use of the concept in $\mathrm{P} \& \mathrm{~W}$ engines. The most recent $\mathrm{P} \& \mathrm{~W}$ combustor TALON X, was developed with support from NASA under the UEET program, and has been selected for the P\&W Geared Turbofan engine on upcoming Airbus, Bombardier and Mitsubishi aircraft. In this effort, $P \& W$ and the United Technology Research Center (UTRC) are investigating multiple injection points and have used modern design and analysis tools to improve the mixing. Initial testing of the concepts was conducted at (UTRC) in an idealized Single Nozzle Rig. Results at $7 \%$ and $30 \%$ power settings for various injector configurations and fuel air ratios demonstrated [92] that all the concepts could have emissions results below the goals set by NASA. A few of the concepts performed very well with NOx emissions levels substantially lower than the NASA goals as well as excellent levels of efficiency. Based on additional testing and analysis an injector concept design was selected and was developed into an advanced 3-cup sector rig. The sector rig was tested at NASA's ASCR facility to measure performance, operability and emissions at test conditions required to calculate the ICAO LTO NOx emissions level. The P\&W sector test results [92] indicated that the P\&W combustor concept had the potential to meet the ERA goals.

The 75\% LTO NOx reduction goal was considered to be a significant challenge for partial pre-mix combustor configurations at the start of ERA Phase 1. ERA pursued partial pre-mix concepts from both $\mathrm{P} \& \mathrm{~W}$ and GE. In addition, as risk mitigation, NASA studied lean direct injection (LDI) concepts from three injector manufacturers in case the partial pre-mix systems showed unresolvable autoignition issues at the higher combustor pressures and temperatures of high OPR engines. Active control strategies were also studied to mitigate any stability issues that may arise for the lean burn concepts. Finally, alternative fuel blends up to $100 \%$ were studied as a possible replacement for Jet-A to improve NOx performance. Details of the ERA Phase 1 testing are described in reference [92]. At the conclusion of Phase 1 testing, the partial pre-mix concepts from both P\&W and GE had shown the potential to meet the LTO NOx goal, without LDI, active combustion control, or alternative fuels. The P\&W concept was chosen for continued technology maturation in ERA Phase 2.

P\&W's lean-lean concept, called the Axial Stage Combustor (ASC) is shown schematically in Figure 38. The ASC concept uses a pilot injector at the front of the combustor for low power conditions. Additional main injectors are used in addition to the pilot injector for high power conditions. The fuel-air mixture is kept lean through the entire axial length of the combustor. The lean burn configuration is necessary to maintain low NOx production at the $\mathrm{N}+2$ cycle conditions as defined in Figure 31 . The LTO NOx performance of ASC concepts was validated in 
the ASCR facility at NASA GRC. Injector/swirler concepts for the sector test at ASCR were pre-screened in flame tube tests at NASA as well as in a sector test at UTRC at lower pressure conditions. The same sector hardware was subsequently tested at ASCR to full engine conditions including sea level take-off conditions to maximum pressure and temperature. The ASC sector was tested over the range of $P_{3} / T_{3}$ conditions estimated for the engine cycle. Pressure, temperature and fuel/air ratio excursions were investigated around each set point to characterize the emissions sensitivity and to better optimize the combustor design. The emission performance of the Phase 2 hardware was good; results from the UTRC sector tests are shown in Figure 39 [103]. Additionally, the sector was tested with a 50/50 blend of alternative fuel to evaluate any fuel flexibility issues. The combustor emissions performance and operability characteristics with the fuel blend were nominally unchanged from the results with Jet-A. The full annular combustor test, which used the same injectors/swirlers as the ASCR sector, was completed in June 2015 at the P\&W full annular combustor facility. These test results confirmed the LTO NOx data from ASCR. The full annular test included thermal paint measurements to assess combustor durability. Complete results from the test will be included in a future publication.

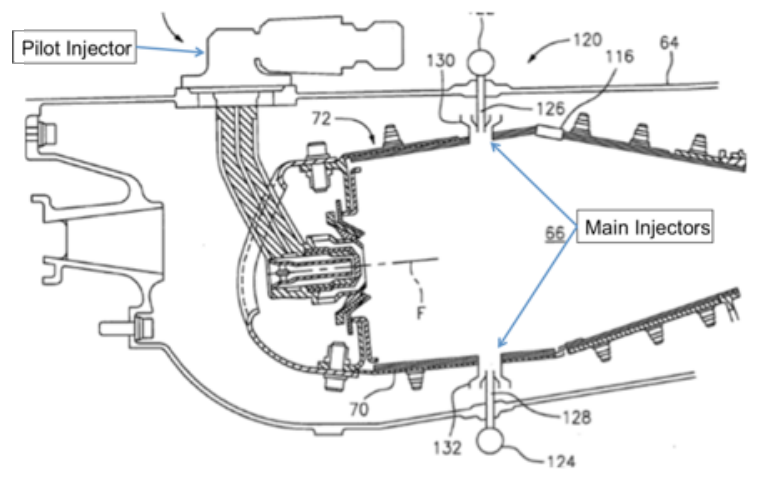

Figure 38. Schematic of Pratt \& Whitney Axial Stage Combustor (ASC) cross-section from U.S. Patent 9,068,748.

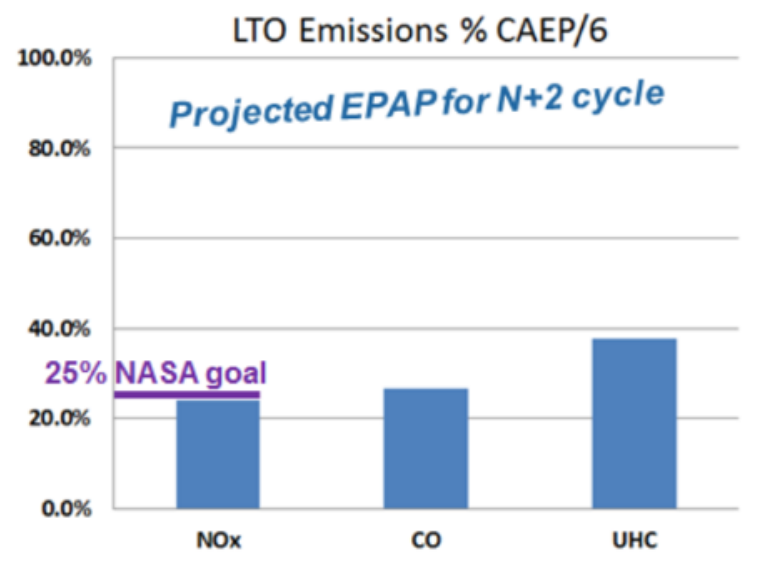

Figure 39. Emissions estimates for the ASC combustor based on sector tests at UTRC. (from Smith, 2015) [103].
WHY NASA? NASA pushed industry to: 1) pursue environmental goals they would not have addressed on their own and 2) to leverage other government agencies and form collaborative teams that would not have occurred without NASA leading the technology development.

The ERA project set very aggressive goals to simultaneously meet the N+2 Aeronautics Subsonic transport goals for reductions of Noise, NOx emissions, and fuel burn as evaluated at the integrated vehicle level. The technologies demonstrated directly support future aircraft with engines incorporating a low fan pressure ratio, and a high bypass ratio propulsor with a lownoise, low-drag nacelle and/ or those with a high power density core engine. During the technology development invaluable data bases were acquired in NASA facilities and documented to support future technology development programs. It is evident that these technologies will appear in the GE9X engine and the family of P\&W GTF ${ }^{\mathrm{TM}}$ engines.

\subsection{CURRENT \& FUTURE NASA COLLABORATIONS}

NASA's advanced vehicle studies, which were aimed at defining concepts to meet the N+3 goals depicted in Figure 31, resulted in new architectures beyond the tube and wing with under wing nacelle configurations common in civil aviation today. Some of these new architectures are shown in Figures 4043. Both the Blended Wing Body concept (Figure 40) and the MIT/Aurora/P\&W Double Bubble Concept (Figure 41) incorporate lifting body fuselages with boundary layer ingesting engines on the upper surface to improve propulsive efficiency and use the fuselage to shield the engine noise from the ground. More electric architectures to improve propulsive efficiency are highlighted in Figures 42 and 43 . Figure 42 depicts a turboelectric distributed propulsion system and Figure 43 depicts a hybrid gas turbine electric propulsion system in which the podded engines supply thrust and provide power to a tail cone thruster that also incorporates boundary layer ingestion by the propulsor to improve propulsive efficiency.

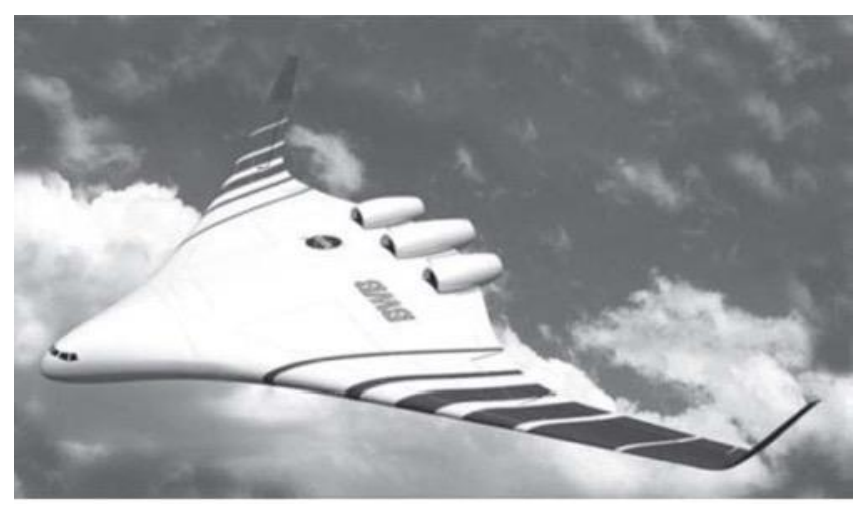

Figure 40. NASA- Boeing blended wing-body concept.

This material is declared work of the U.S. Government and is approved for public release; distribution is unlimited. 


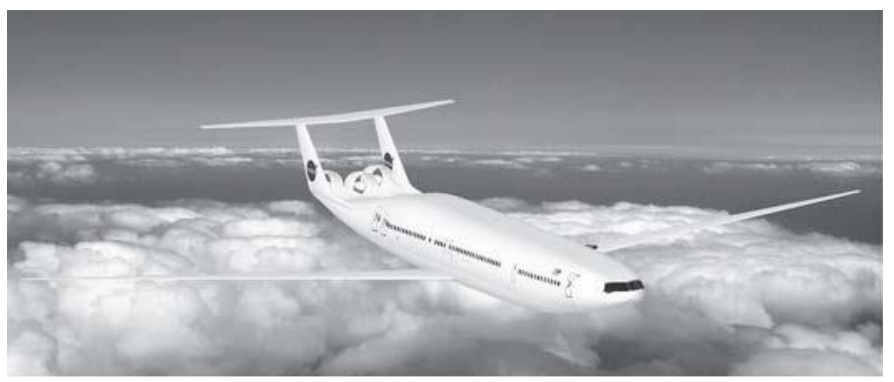

Figure 41. MIT, Aurora, and P\&W double bubble aircraft concept - electric or motor driven.

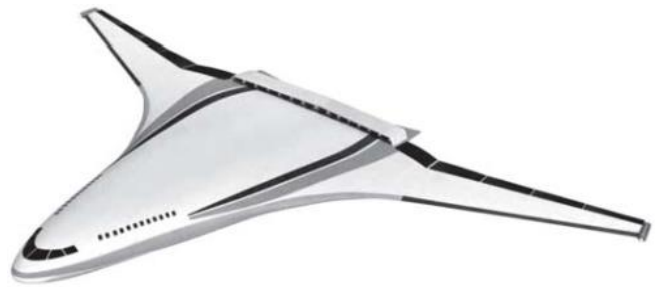

Figure 42. NASA turboelectric distributed propulsion concept note electric.

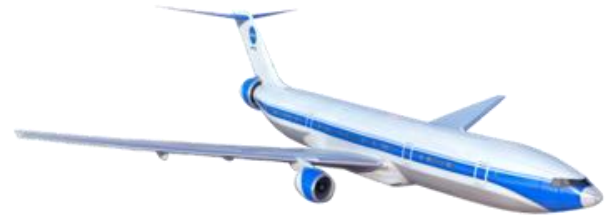

Figure 43. NASA Single-aisle Turboelectric Aircraft with an Aft Boundary-Layer propulsor (STARC-ABL) hybrid electric concept.

Embedded engines with boundary layer ingestion offer an additional fuel burn benefit of up to $5 \%$ to $10 \%$ because of their reacceleration of fluid that had been slowed by the viscous drag of the vehicle. This technology benefits the propulsive efficiency of the vehicle as described in Figure 44 by reducing the jetting velocity compared to that of a podded engine and by reducing the vehicle wake deficit. The potential benefit depends upon the percentage of the boundary layer from the vehicle ingested into the engines, so some concepts attempt to capture a larger percentage of this boundary layer by using distributed propulsors across the upper surface of the vehicle. Blended-wing-body vehicles offer an attractive method to leverage boundary-layeringesting (BLI) engines because of their larger surface area, which results in a larger boundary layer and in more flexibility of engine mounting on the upper surface of the lifting body.
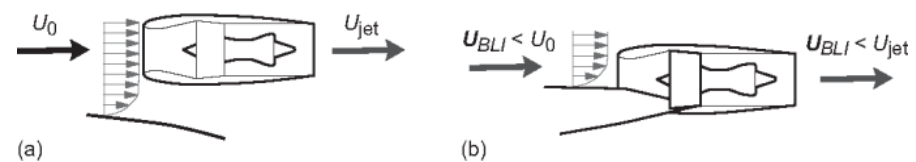

Figure 44. Propulsion benefits of boundary layer ingestion (BLI) due to the fact that propulsive efficiency approaches $100 \%$ as the jet exit velocity $\left(U_{\text {jet }}\right)$ is reduced to the flight speed of the vehicle.
One of the challenges for BLI engines, however, is the potential loss in fan efficiency and degradation of life due to the inlet distortion and resulting unsteady forces imposed on the rotating fan. NASA collaborated with UTRC to investigate integrated inlet and fan designs that mitigate the negative impact of the inlet distortion on fan efficiency and operability. The goal was to demonstrate an embedded integrated inlet and distortiontolerant fan system that provides the identified aircraft benefits by achieving less than a $2 \%$ loss in fan efficiency while maintaining ample stability margin. The study used an existing NASA Research Announcement (NRA) sponsored blendedwing-body design such as that depicted in Figure 40, to define the design constraints for the inlet boundary layer and the requirements for a relevant embedded engine configuration. NASA partnered with UTRC, Pratt \& Whitney, and Virginia Polytechnic and State University (Virginia Tech) through the NRA to exploit the optimal design space and to design and build an integrated inlet and fan embedded system. A sampling of the relevant publications supporting this activity including the simulated aircraft boundary layer, the embedded inlet and distortion tolerant fan design, and the aeromechanics analysis is found in References [104-110].
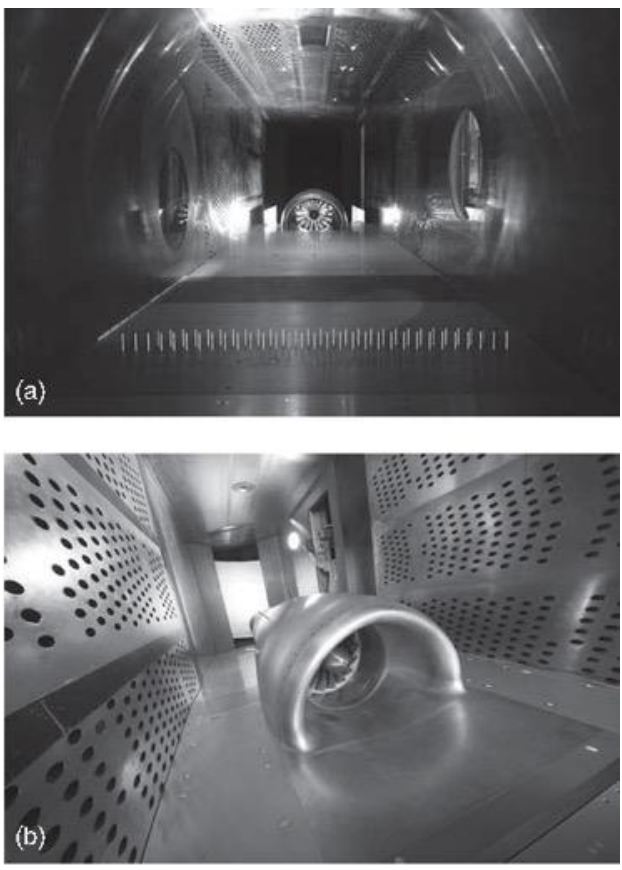

Figure 45. Boundary layer ingesting $(B L I)$ fan test rig installed in NASA Glenn $8-$ by 6 -Foot Supersonic Wind Tunnel ( $8 \times 6$ SWT). (a) Bars upstream of fan are used to thicken boundary layer, and downstream bleed plates are used to customize boundary layer upstream of fan inlet. (b) close-up of the integrated inlet and fan installation in the $8 \times 6$ SWT.

NASA recently completed the testing of a distortion-tolerant fan with a relevant boundary layer inflow field in the 8- by 6 Foot Supersonic Wind Tunnel at GRC. The arrangement of this embedded propulsor experiment is shown in Figure 45. A false floor was inserted in the tunnel to mount the inlet/fan hardware. 
Note that the rods located far upstream of the embedded fan inlet provide a thick inlet boundary layer. Downstream of the rods and upstream of the inlet, the false floor contains a porous section to provide bleed control to adjust the incoming fan/inlet boundary layer to simulate that of a hybrid wing-body vehicle such as the one shown in Figure 41. The first phase of testing was completed in summer of 2017. Much learning was achieved in the initial test and a summary of the results are provided in reference [111]. However, it was evident from these results that the following tool improvements are required: 1) integrated inlet fan design tools, 2) integrated vehicle inlet design and analysis tools, and 3) aeromechanics and fluid structural interaction analysis and assessment tools.

More electric and Hybrid Gas turbine Electric Propulsion (HGEP) vehicles open a vast design trade space by simply allowing a decoupling of the propulsor and power generator. This decoupling opens the possibility for highly distributed propulsors that can be arranged to optimize the airframe drag and control services; thereby providing propulsive efficiency improvements as well as reductions in noise and emissions. These improvements come at a cost of additional airport and vehicle infrastructure and the complexity that the vehicle, powertrain, and controls be highly integrated as well as designed concurrently. In addition, powered electronics and batteries require additional safety considerations and produce significant amounts of heat. Unlike the gas turbine engine where the waste heat is ejected out the exhaust nozzle to the atmosphere, the electronics heat is low quality heat and will require additional thermal management systems to transport the heat from the source. An additional challenge is that the specific technical barriers for these advanced vehicle architectures is highly configuration specific. However, due to the potential benefit of these HGEP vehicles, it is necessary to investigate these technical issues.

It is evident that HGEP configurations are much less mature and require significant improvements in tools to estimate the weight, volume, power density, efficiency and reliability of the electrical components to perform basic system studies. To this end, NASA has released a series of NRA's focused on developing high power density motors/generators, AC/DC power converters, and integrated controls and power management. Furthermore, NASA has invested in the development of the NEAT (NASA Electric Aircraft Testbed) facility to enable development and testing of electrical components of large-scale electric aircraft powertrains. The facility has a reconfigurable architecture that industry, academia, and government can use to evaluate the efficiency, power distribution and controls of the electrical components to further mature HGEP vehicles. Investments to understand the impact of power extraction on the turbine engine and how to leverage the electronic components to optimize the HGEP system has been severely lacking. A dedicated approach to understand the impact of power extraction on the design and operability of the gas turbine engine is required. In addition, integrated power and thermal management of the gas turbine with the electrical components and vehicle will be a key technology that needs to be further developed to make these systems realizable for large aircraft.

For high-speed flight, NASA Supersonics activities are focused on minimizing the sonic boom and working with the FAA to determine acceptable noise levels for supersonic flight over land. When the FAA requirements are determined, the next major challenge will be to maximize engine efficiency at cruise and address the landing and take-off noise near the airport. To satisfy both these competing requirements, a variable cycle engine with high bypass at takeoff (to address noise requirements) and low bypass ratio at cruise (to reduce SFC) will likely be required. Furthermore, emissions at high altitude cruise could become a major barrier.

In summary, it is clear that the propulsion system will be highly integrated with the vehicle inclusive of controls, power, and thermal management. In addition, the gas turbine engine will remain the prime source of power generation for the foreseeable future for larger aircraft ( $>75$ passengers). Therefore, it is essential to continue to develop and demonstrate high power density and highly efficient core engines with adaptive features to better integrate with the varying load demands of the electrical components. Furthermore, additive manufacturing, more distributed propulsion via hybrid gas turbine electric propulsion systems, and new multidisciplinary design tools inclusive of machine learning will open the design space and may generate vehicles and concepts significantly different than those we are familiar with today. An additional challenge is that the specific technical barriers for these advanced vehicle architectures is highly configuration specific. Therefore, it is necessary for the gas turbine community to identify a set of technology barriers that are common to many of these future architectures and identify common model problems that the community can work together to enhance and validate their respective design and analysis tools. Subsequently, tool assessment exercises and system demonstrations are suggested to anchor the capability of these enhanced tools.

\subsection{SUMMARY \& CONCLUDING REMARKS}

The history of the NASA Glenn Research Center (1940 to present) coincides with an era of dramatic reductions in aircraft fuel burn, emissions, and noise, largely attributed to improvements in the engine. NASA GRC has contributed greatly to this improvement through full engine testing; engine component testing and development; analytical tool and model development; research investigating fundamental flow physics; and computational fluid dynamics validation; all in partnership with the aircraft engine community. NASA has a distinctive role in advancing gas turbine engine technology because the government has the expertise, facilities, and flexibility to pursue impactful research in depth and the ability to share detailed precompetitive research results. Furthermore, NASA is uniquely positioned to work with industry, academia, and other government agencies on proprietary and export-controlled technologies; thereby enabling NASA to understand the needs of civilian and military aviation and to form collaborations that provide technologies that are beneficial to the entire gas turbine 
community. This paper reviewed NASA's role and contributions to turbine engine development, specific to both 1) NASA's role in conducting experiments to understand flow physics and provide relevant benchmark validation experiments for (CFD) code development, validation, and assessment, and 2) the impact of technologies resulting from NASA collaborations with industry, academia and other government agencies. In addition to the technical contributions and impact to the gas turbine community, the paper highlighted the following intangible attributes that NASA brings to the team developing the technology:

- NASA's flexibility to explore beyond the original scope to maximize learning and provide reliable benchmark data sets for the gas turbine community.

- NASA's flexibility to create and leverage collaborations to continue technology development from theory to engine component demonstration.

- NASA's ability to explore high-risk, high-benefit technologies that industry would not pursue on its own.

- NASA's collaborations involving NASA's CFD codes and facilities thereby; providing the capability to share results with the community that otherwise would not have been shared.

- NASA's resourcefulness to leverage other government agencies and form collaborative teams that would not occur without NASA leading the technology development.

- NASA's collaborations set aggressive performance and environmental goals that would not be addressed without NASA involvement.

Are NASA technology investments still needed to enable future turbine engine-based propulsion systems? Given the potential for advanced architectures employing BLI or hybrid electric propulsion will NASA be needed to help develop the design and analysis tools, databases, and technology demonstration programs to meet the challenges? This of course is for the industry and the gas turbine engine community to decide. To this end, GE and P\&W provided an overview slide depicting their perspective of NASA's impact on their products of the past and where they seek NASA participation in the future. GE provided a roadmap for their next generation future 'Additive Analytical Affordable Engine' - see Figure 46. GE shows the NASA and government technology collaboration projects and/or programs in the upper curve and the GE products on the lower curve. It is interesting to note from Figure 46 that GE reports NASA's $\$ 200 \mathrm{M}$ investment in the $\mathrm{E}^{3}$ project enabled \$3 Billion dollars of industry investment resulting in \$35 Billion dollars of sales and the generation of 15,000 jobs over a 30 -year period of impact. Similarly, P\&W has provided a technology roadmap showing how NASA and $\mathrm{P} \& \mathrm{~W}$ collaborative development and test campaigns have impacted the development of the geared turbofan engine and next generation UHB propulsor- see Figure 47. Per Figure 47, P\&W GTF ${ }^{\mathrm{TM}}$ provided a $16 \%$ reduction in fuel consumption, $50 \%$ reduction in regulated emissions, $75 \%$ reduction in noise footprint and more than 9000 new engine orders from 80 different customers. From Figures 46 and 47, it is apparent NASA has clearly played a key role in advancing technologies for turbine engine development. In conclusion, NASA is well-positioned and eager to continue our legacy to form collaborations that provide technologies that are beneficial to the entire gas turbine community.

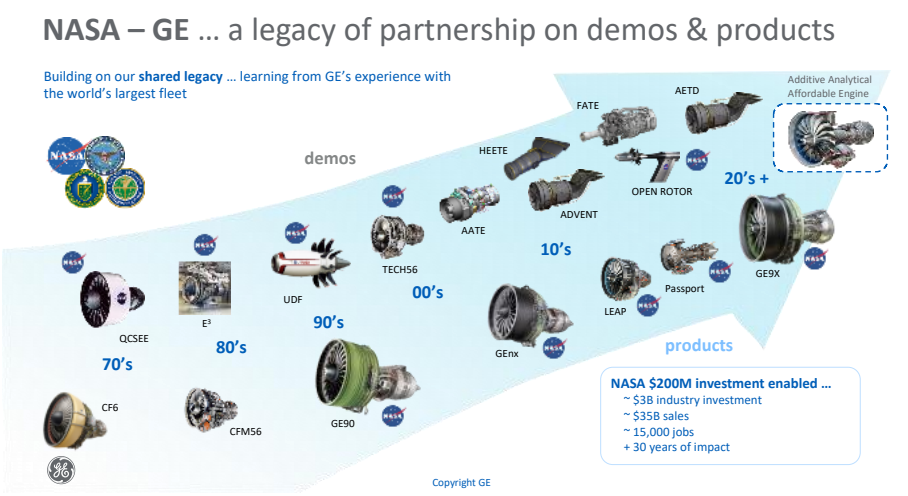

Figure 46. GE perspective of NASA Impact on their product development due to NASA Partnerships and technology demonstrations. Chart provided courtesy of GE: Copyright GE.

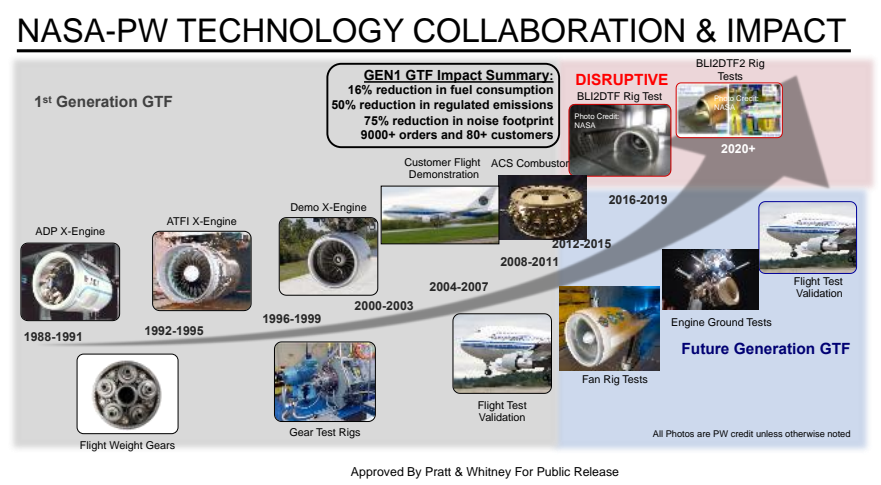

Figure 47. P\&W perspective of NASA Impact on their product development due to NASA Partnerships and technology demonstrations. Chart provided courtesy of P\&W: Copyright P\&W.

\section{NOMENCLATURE}

ACE Alternative Concept Engine

ACEE Aircraft Energy Efficiency (program)

AFRL Air Force Research Laboratory

ARMD Aeronautics Research Mission Directorate

ASC Axial Stage Combustor

ASCR Advanced Subsonic Combustion Rig

AVSPOT Advanced Variable Speed Power Turbine (Program)

BLI Boundary Layer Ingesting 


\begin{tabular}{|c|c|}
\hline BPR & Bypass Ratio \\
\hline CAEP & Committee on Aircraft Environmental Protection \\
\hline CFD & Computation Fluid Dynamics \\
\hline CLEEN & Continuous Lower Emissions and Noise \\
\hline DMRJ & Dual Mode Ramjet \\
\hline EPA & Environmental Protection Agency \\
\hline ERA & Environmentally Responsible Aviation (project) \\
\hline ERB & Engine Research Building \\
\hline$E^{3}$ & Energy Efficient Engine (project) \\
\hline FAA & Federal Aviation Administration \\
\hline FPR & Fan Pressure Ratio \\
\hline GE & General Electric \\
\hline GRC & Glenn Research Center \\
\hline $\mathrm{GTF}^{\mathrm{TM}}$ & Geared Turbofan \\
\hline $\mathrm{H}$ or $\mathrm{h}$ & Enthalpy \\
\hline HGEP & Hybrid Gas turbine / Electric Propulsion \\
\hline ICAO & International Committee on Aircraft Operations \\
\hline IGV & Inlet Guide Vane \\
\hline LPT & Low Pressure Turbine \\
\hline LCTR & Large Civil Tiltrotor \\
\hline LDI & Lean Direct Injection \\
\hline LDV & Laser Doppler velocimetry \\
\hline LE & Leading Edge \\
\hline LTO & Landing and Take-Off \\
\hline OPR & Overall Pressure Ratio \\
\hline M & Mach Number \\
\hline$M_{\text {rel }}$ & Relative Mach Number \\
\hline MCP & Maximum Continuous Power \\
\hline MIT & Massachusetts Institute of Technology \\
\hline MRP & Maximum Rated Power \\
\hline NACA & National Aeronautics \\
\hline NASA & National Advisory Committee for Aeronautics \\
\hline NOx & oxides of nitrogen \\
\hline NRA & NASA Research Announcement \\
\hline OGV & Outlet Guide Vane \\
\hline OPEC & Organization of Petroleum-Exporting Countries \\
\hline OTR & Over the Rotor \\
\hline $\mathrm{P}_{4}$ & Total pressure far downstream of the blade \\
\hline$P_{\text {ref }}$ & Reference pressure (standard day inlet). \\
\hline PS & Pressure Surface \\
\hline$P_{3}$ & Combustor entrance pressure \\
\hline $\mathrm{P} \& \mathrm{~W}$ & Pratt \& Whitney \\
\hline $\operatorname{Re}_{c x}$ & Reynolds number based on axial chord \\
\hline RVLT & Revolutionary Vertical Lift Technology (project) \\
\hline SOA & State-of the Art \\
\hline SHP & Shaft Horse Power \\
\hline SS & Suction Surface \\
\hline SV & Soft Vane \\
\hline TAPS & Twin Annular Premixing Swirler \\
\hline$T_{3}$ & Combustor entrance temperature \\
\hline ТВCC & Turbine Based Combined Cycle \\
\hline TRL & Technology Readiness Level \\
\hline TSFC & Thrust Specific Fuel Consumption \\
\hline $\mathrm{T}_{\mathrm{ip}}$ & Rotational speed of the wheel at the mean tip radius \\
\hline UDF & Unducted Fan \\
\hline UEET & Ultra Efficient Engine Technology \\
\hline
\end{tabular}

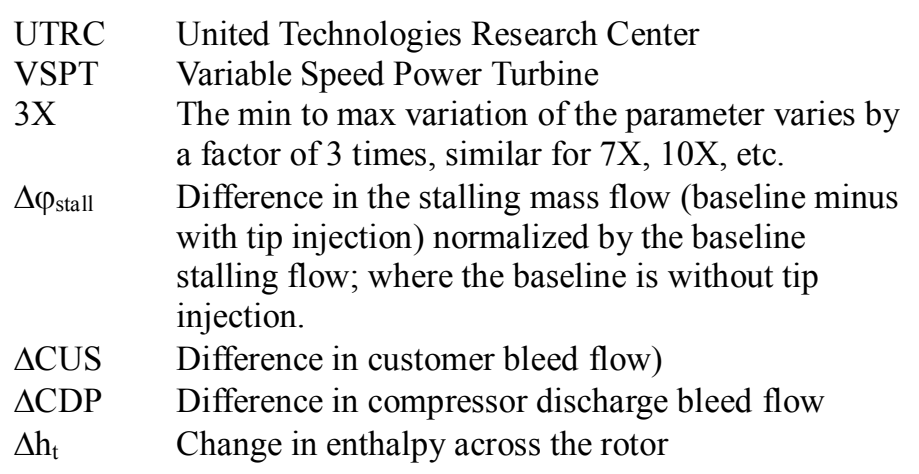

\section{REFERENCES}

[1] Epstein, A. H. 2014. Aeropropulsion for commercial aviation in the twenty-first century and research directions needed, AIAA Journal 52(5):901-911, doi:10.2514/1.J052713.)

[2] Bullock, R. O., and Johnsen, I. A. 1965. Aerodynamic design of axial flow compressors. NASA SP-36.

[3] Glassman, Arthur J., ed., 1972, "Turbine Design and Application", NASA SP-290.

[4] Bowles, M. D. 2010. The "Apollo" of aeronautics: NASA's aircraft energy efficiency program, 1973-1987. NASA ebook,

http://www.nasa.gov/connect/ebooks/aero_apollo_detail.h tml (accessed August 31, 2016).

[5] Ciepluch, C. C., Davis, D. Y., and Gray, D. E. 1987. Results of NASA's energy efficient engine program. J. Propul. Power 3:560-568.

[6] Davis, D. Y., and Stearns, E. M. 1985. Energy efficient engine: flight propulsion system final design and analysis. NASA CR-168219.

[7] Strazisar, A. J. 1985. Investigation of flow phenomena in a transonic fan using laser anemometry. J. Eng. Power-T. ASME 107:427-436.

[8] Hathaway, M. D., Gertz, J. B., Epstein, A. H., and Strazisar, A. J. 1986. Rotor wake characteristics of a transonic axial flow fan. AIAA J. 24:1802-1810.

[9] Wood, J. R., Strazisar, A. J., and Simonyi, P. S. 1987. Shock structure measured in a transonic fan using laser anemometry. AGARD-CP-401.

[10] Strazisar, A. J., Wood, J. R., Hathaway, M. D., and Suder, K. L. 1989. Laser anemometer measurements in a transonic axial-flow fan rotor. NASA TP-2879.

[11] Suder, K. L., Okiishi, T. H., Hathaway, M. D., Strazisar, A. J., and Adamczyk, J. J. 1987. Measurements of the unsteady flow field within the stator row of a transonic axial-flow fan: Part I-measurement and analysis technique. ASME Paper 87-GT-226.

[12] Hathaway, M. D., Okiishi, T. H., Suder, K. L., Strazisar, A. J., and Adamczyk, J. J. 1987. Measurements of the unsteady flow field within the stator row of a transonic axial-flow fan: Part II- results and discussion. ASME Paper 87-GT-227. 
[13] Suder, K.L., 1996. "Experimental Investigation of the Flow Field in a Transonic Axial Flow Compressor with Respect to the Development of Blockage and Loss." Ph.D. Dissertation Case Western Reserve University, also NASA TM107310, August 1996.

[14] Suder, K.L., and Celestina, M.L., 1996. "Tip Clearance Vortex / Shock Interactions in a Highly Loaded Transonic Compressor Rotor." J. Turbomach, Vol. 118, no. 2, 1996, pp. 218-229.

[15] Suder, K.L., 1998. "Blockage Development in A Transonic, Axial Flow Compressor", J. Turbomach., Vol. 120, No. 3, 1998, pp.465-476.

[16] Reid, L., and Moore, R. D. 1978. Design and overall performance of four highly loaded, high speed inlet stages for an advanced, high-pressure-ratio core compressor. NASA TP-1337.

[17] Dunham, J. 1998. AGARD WG26 report - summary of 13 different simulations of Rotor 37 AGARD Advisory Report AR-355, May 1998 CFD Validation for Propulsion System Components. Also summarized in ASME 98-GT-050.

[18] Denton, J., 1996. "Lessons Learned from Rotor 37. Presented at the Third International Symposium on Experimental and Computational

Aerothermodynamics of Internal Flows (ICIASF), Beijing, China, September 1-6, 1996.

[19] Dalbert and Wiss. 1995 "Numerical Transonic Flowfield Predictions for NASA Compressor Rotor 37," ASME 95GT-326.

[20] Arima, T.A., Sonoda, T., and Masatoshi, S. A. 1997. Numerical Investigation of Transonic Axial Compressor Rotor Flow Using a Low Reynolds Number k-epsilon Turbulence Model (R37 and R67) ASME 97-GT-082.

[21] Arima, T., Masatoshi, S, and Yamaguchi, Y. 1998. The Flow Field in the Tip Clearance Region of an Axial Compressor Rotor.

[22] Arima, T., Sonoda, T., Shirotori, M., and Yamaguchi, Y. 1998. Computation of Subsonic and Transonic Compressor Rotor Flow Taking Account of Reynolds Stress Anisotropy. ASME 98-GT-423.

[23] Calvert, W, J., A Synthesis of NASA Compressor Rotor 37 Using a 3D CFD Code Proceedings of "Verification of Design Methods by Test and Analysis," Royal Aeronautical Society, www.raes.org.uk.

[24] Chima, R. 1996. A K-omega Turbulence Model for QuasiThree-Dimensional Turbomachinery Flows, NASA TM10705, AIAA Reno Meeting, 1996.

[25] Chima, R. 1998. Calculation of Tip Clearance Effects in a Transonic Compressor Rotor, ASME J of Turbo, Vol. 120, p. 131-140, 1998.

[26] Shabbir, A. 1996. Assessment of Three Turbulence Models in a Compressor Rotor 96-GT-198.

[27] Hah and Loellbach. 1997. Development of Hub Corner Stall and Its Influence on the Performance of Axial Compressor Blade Rows, ASME 97-GT-042 (to be published in ASME J. of Turbomachinery).
[28] Shabbir, A.,1997. The Effect of Hub Leakage Flow on Two High Speed Axial Compressor Rotors, ASME 97-GT-346 (to be published in ASME J. of Turbomachinery).

[29] Arnone, A. 1997. Grid Dependency Study for the NASA Rotor 37 Compressor Blade ASME 97-GT-384.

[30] Calvert, J. 1997. Evaluation of a 3D Viscous Code for Turbomachinery Flows, ASME 97-GT-078.

[31] Van Zante, D. E., Adamczyk, J. J., Strazisar, A. J., and Okiishi, T. H. 2002. Wake recovery performance benefit in a high-speed axial compressor. J. Turbomach. 124:275284.

[32] Hathaway, M. D., Chriss, R. M., Wood, J. R., and Strazisar, A. J. 1993. Experimental and computational investigation of the NASA low-speed centrifugal compressor flow field. J. Turbomach., 115:527-542.

[33] Skoch, G. J., and Moore, R. D. 1987. Performance of two $10-\mathrm{lb} / \mathrm{sec}$ centrifugal compressors with different blade and shroud thicknesses operating over a range of Reynolds numbers. NASA TM-100115 (AVSCOM-TR-87-C-21 and AIAA-87-1745).

[34] Skoch, G. J., Prahst, P. S., Wernet, M. P., Wood, J. R., and Strazisar, A. J. 1997. Laser anemometer measurements of the flow field in a 4:1 pressure ratio centrifugal impeller. NASA TM-107541 (ARL-TR-1448 and ASME Paper 97GT-342).

[35] Giel, P. W., Van Fossen, G. J., Boyle, R. J., Thurman, D. R., and Civinskas, K. C. 1999. Blade heat transfer measurements and predictions in a transonic turbine cascade. NASA/TM-1999-209296.

[36] Giel, P. W., D. R. Thurman, G. J. VanFossen, S. A. Hippensteele, and R. J. Boyle, 1998. "Endwall Heat Transfer Measurements in a Transonic Turbine Cascade," J. Turbomach., Vol. 120, No. 2, pp. 305-313, April 1998.

[37] Durbin, P. A., and Pettersson Reif, B. A. 2001. Statistical Theory and Modeling for Turbulent Flows. New York, NY: John Wiley \& Sons.

[38] Adamczyk, J. J. 1984. Model equation for simulating flows in multistage turbomachinery. NASA TM-86869.

[39] Celestina, M. L., and Mulac, R. A. 2009. Assessment of stage 35 With APNASA. AIAA 2009-1057.

[40] Herrick, G. P., Hathaway, M. D., and Chen, J. 2009. Unsteady full annulus simulations of a transonic axial compressor stage. AIAA 2009-1059.

[41] Ameri, A. A. 2009. NASA ROTOR 37 CFD CODE validation: Glenn-HT code. AIAA 2009-1060.

[42] Hah, C. 2009. Large eddy simulation of transonic flow field in NASA Rotor 37. AIAA 2009-1061.

[43] Chima, R. V. 2009. SWIFT code assessment for two similar transonic compressors. AIAA 2009-1058.

[44] Suder, K. L., Chima, R. J., Strazisar, A. J., and Roberts, W. B. 1994. "The Effects of Adding Roughness and Thickness to a Transonic / Supersonic Axial Compressor Rotor." $J$. Turbomach., Vol. 117, no. 4, 1994, pp. 491-505.

[45] Roberts, W. B., 1995, "Advanced Turbofan Blade Refurbishment Technique," J. Turbomach., Tech. Brief, Vol. 117, pp 666-667. 
[46] Roberts, W. B., Armin, A., Kassaseya, G., Suder, K. L., Thorp, S. A., and Strazisar, A. J., 2002. "The Effect of Variable Chord Length on Transonic Axial Rotor Performance,", J. Turbomach., Vol. 124, pp. 351-356, July, 2002.

[47] Roberts, W. B., Prahst, P. S., Thorp, S., Strazisar, A.J. 2005. "The Effect of Ultrapolish on a Transonic Axial Rotor," ASME GT2005-69132, proceedings of the ASME Turbo Expo 2005, June 6-9, 2005, Reno, Nevada.

[48] Berdanier, R. A., and Key, N. L., 2015. “An Experimental Investigation of the Flow Physics Associated with End Wall Losses and Large Rotor Tip Clearances as Found in the Rear Stages of a High Pressure Compressor, NASA/CR-2015-218868.

[49] Volino, R. J., 2011. Experimental and Computational Investigation of Unsteady Endwall and Tip Gap Flows in Gas Turbine Passages, Final Report for NASA Interagency Agreement NNC11IA11I. June 2011-Septtember 2016, delivered Jan 25, 2017.

[50] Katz, J. 2017. "High Resolution Measurements of the Effects of Tip Geometry on Flow Structure and Turbulence in the Tip Region of a Rotor Blade. Final Report for NASA Grant/ Cooperative Agreement Number: NNX11AI21A for the period of June 6, 2011-July 31, 2016. Final Report Delivered February 2017.

[51] Weigl, H. J., Paduano, J. D., Frechette, L. G., Epstein, A. H., Greitzer, E. M., Bright, M. M., and Strazisar, A. J. 1998. "Active Stabilization of Rotating Stall and Surge in a Transonic Single Stage Axial Compressor," J. Turbomach., Vol. 120, 1998, No. 4, pp. 625-636.

[52] Spakovszky, Z. S., Weigl, H. J., Paduano, J. D., Van Schalkwyk, C. M., Suder, K. L., Bright, M., and Strazisar, A. J. 1998. "Rotating Stall Control in a High-Speed Stage with Inlet Distortion, Part I - Radial Distortion", J. Turbomach., Vol. 121, 1999, pp. 510-516.

[53] Spakovszky, Z. S., Weigl, H. J., Paduano, J. D., Van Schalkwyk, C. M., Suder, K. L., Bright, M., and Strazisar, A. J. 1999. "Rotating Stall Control in a High-Speed Stage with Inlet Distortion, Part II - Circumferential Distortion", J. Turbomach., Vol. 121, 1999, pp. 517-524.

[54] Suder, K. L., Hathaway, M. D., Thorp, S. A., Strazisar, A. J., and Bright, M. M. 2001. "Compressor Stability Enhancement Using Discrete Tip Injection”, $J$. Turbomach., Vol. 123, No. 1, pp. 14-23, January, 2001.

[55] Strazisar, A. J., Bright, M. M., Thorp, S. A., Culley, D., Suder, K. L, and Prahst, S. 2004. "Compressor Stall Control Through Endwall Recirculation", ASME GT200454295 in Proceedings of the ASME Turbo EXPO 2004 Power for Land, Sea, and Air, June 14-17, 2004 selected for ASME Journal.

[56] Suder, Kenneth. L., and Thomas, Scott, R. 2009. "An Overview of the NASA Hypersonic Project's Combined Cycle Engine Mode Transition Research Experiment," Paper 0664 at the JANNAF (Joint Army, Navy, NASA, Air Force) 43rd CS/31st APS/25th PSHS Joint Meeting; La Jolla, CA Dec 7-11,2009.
[57] Auslender, Aaron, Suder, Kenneth. L., and Thomas, Scott, R. 2009. "An Overview of the NASA FAP Hypersonics Project Airbreathing Propulsion Research" AIAA Paper 185450 published and presented at the AIAA International Space Planes and Hypersonic Systems Conference; Bremen, Germany October, 2009.

[58] Sanders, B. W.; and Weir, L. J. 2008. "Aerodynamic Design of a Dual-Flow Mach 7 Hypersonic Inlet System for a Turbine-Based Combined-Cycle Hypersonic Propulsion System," NASA-CR-2008-215214, May 2008.

[59] Bilardo V.J., Curran F.M., Lovell N.T., and Maggio G., 2003, "Benefits of Airbreathing Launch Systems for Access to Space" AIAA 2003-5265, 39th Joint Propulsion Conference

[60] Shafer D.G., McNelis N., 2003, "Development of a Ground Based Mach 4+ Revolutionary Turbine Accelerator Technology Demonstrator (RTATD) for Access to Space" ISOABE 2003.

[61] "RTA Propulsion System Data Requirements/Boeing TSTO Study from NASA Glenn”, RASER Contract NAS301135, 2002.

[62] Mielke, M., 2009 "RTA / GE57 Subscale Fan Rig, Final Report - Mechanical Design” NASA CR-2010-215814.

[63] Mielke, M., Clark, D., and Wood, P. 2009 "RTA / GE57 Subscale Fan Rig, Final Report - Aerodynamic Test Results “, NASA CR-2009-215816.

[64] Suder, K.L, Adamczyk, J.J., Wood, P., Zenon, R., Mielke, M., Powell, B., LaChapelle, D. 2005. "Design and Analysis of a Mach 4 Capable Fan Stage for the RTA Turbine Based Combined Cycle Propulsion System, Proceedings for the JANNAF 40th Combustion Science and 28th Air Breathing Propulsion Meeting June 13-17, 2005 Charleston, SC.

[65] Suder, K.L., Prahst, S. Thorp, S.A. 2010. "Results of an advanced Fan Stage Operating over a Wide Range of Speed \& Bypass Ratio - Part I: Fan Stage design and Experimental Results", ASME GT2010-22825 In Proceedings of the ASME Turbo EXPO 2010, June 14-19, 2010 .

[66] Celestina, M.L., Suder, K.L., Kulkarni, S. 2010. "Results of an advanced Fan Stage Operating over a Wide Range of Speed \& Bypass Ratio - Part II: CFD and Experimental Results", ASME GT2010-23386 In Proceedings of the ASME Turbo EXPO 2010 June 14-19, 2010.

[67] Snyder, C. A., and Acree, C. W. 2012. "Preliminary Assessment of Variable Speed Power Turbine Technology on Civil Tiltrotor Size and Performance," AHS 68th Annual Forum, Fort Worth, TX, May 2012.

[68] Snyder, C. A. 2014. "Exploring advanced technology gas turbine engine design and performance for the Large Civil Tiltrotor (LCTR)", 50th AIAA/ASME/SAE/ASEE Joint Propulsion Conference, Cleveland, OH, July 28-30, 2014.

[69] Acree, C. W. and Snyder, C. A. 2012. "Influence of Alternative Engine Concepts on LCTR2 Sizing and Mission Profile," AHS Future Vertical Lift Aircraft Design Conference, San Francisco, CA, January 2012.

This material is declared work of the U.S. Government and is approved for public release; distribution is unlimited. 
[70] Robuck, M., Wilkerson, J. B., Maciolek, R., Vonderwell, D. 2013. "The Effect of Rotor Cruise Tip Speed, Engine Technology and Engine/Drive System RPM on the NASA Large Civil Tiltrotor (LCTR2) Size and Performance," NASA/CR-2013-216593, March 2013.

[71] Robuck, M., Wilkerson, J. B., Snyder, C. A., Zhang, Y., Maciolek, B. 2013. "Study and Sub-System Optimization of Propulsion and Drive Systems for the Large Civil Tiltrotor (LCTR2) Rotorcraft," AHS 69th Annual Forum, Phoenix, Arizona, May 2013, also NASA TM-2013218103, December 2013.

[72] D'Angelo, M., 1995. "Wide Speed Range Turboshaft Study," NASA/CR - 1995-198380, Aug, 1995.

[73] Snyder, C. A. and Thurman, D. R., Gas Turbine Characteristics for a Large Civil Tilt-Rotor (LCTR), Proc. AHS Int. 65th Annual Forum, May, 2009.

[74] Welch, G. E. and Boyle, R. J. 2010. "Assessment of aerodynamic challenges of a variable-speed power turbine for Large Civil Tilt-Rotor application," 66th Annual Forum of the American Helicopter Society, Phoenix, May 10-12, 2010.

[75] Welch, G. E., McVetta, A. B, Stevens, M. A., Howard, S. A.; Giel, P. W.; Ameri, A. A., To, W., Skoch, G. J.; Thurman, D. R. 2012. "Variable-Speed Power-Turbine Research at Glenn Research Center," AHS International, 68th Annual Forum and Technology Display, Fort Worth, Texas, May 2012, NASA TM-2012-217605, July 2012.

[76] Howard, S. A. 2012. "Rotordynamic Feasibility of a Conceptual Variable-Speed Power Turbine Propulsion system for Large Civil Tilt-Rotor Applications," NASA/TM-2012-217134, Jul 2012.

[77] Ford, A., Turner, E., Bloxham, M., Gegg. S., King, B., Harris, C., Bell, M., Eames, D. 2012. "Variable-Speed Power-Turbine Component Research Plan," NASA/CR2012-217423, Feb. 2012 (Export Controlled, unlimited rights).

[78] Suchezky, M., Cruzen, C. S. 2012. Variable-Speed Power Turbine for the Large Civil Tilt Rotor," NASA/CR-2012217424, Feb. 2012 (Unlimited rights).

[79] Flegel-McVetta, A. B., Giel, P. W., Welch, G. E., Ames, Forrest, A. and Long, Jonathon, A. 2015. "Complimentary Aerodynamic Datasets for Variable-Speed Power-Turbine Blade Section from Two Independent Transonic Turbine Cascades," Paper ISABE 2015-20163, International Society of Air-Breathing Engines (ISABE) Conference, Phoenix, AZ, July 2015.

[80] Flegel-McVetta, A. B., Giel, P. W., and Welch, G. E. 2014. "Aerodynamic Effects of High Turbulence Intensity on a Variable-Speed Power-Turbine Blade with Large Incidence and Reynolds Number Variations," Paper AIAA-20143933, 50th AIAA/ASME/SAE/ASEE Joint Propulsion Conference, Cleveland, OH, July 2014.

[81] McVetta, A. B., Giel, P. W., and Welch, G. E. 2013. "Aerodynamic Measurements of a Variable-Speed PowerTurbine Blade Section in a Transonic Turbine Cascade at
Low Inlet Turbulence," GT2013-94695 for IGTI 2013 Turbo Expo Conference, San Antonio, TX, June 2013.

[82] McVetta, A. B., Giel, P. W., Welch, G. E. 2012. Aerodynamic Investigation of Incidence Angle Effects in a Large Scale Transonic Turbine Cascade," AIAA-20123879 , Proc. $48^{\text {th }}$ AIAA/ASME/SAE/ASEE Joint Propulsion Conference \& Exhibit, Atlanta, GA, Jul-Aug. 2012.

[83] Mihelish, M. and Ames, F.E., 2013, "The development of a closed loop high speed cascade wind tunnel for cascade testing at moderate to low Reynolds numbers", ASME/GT2013-95048, 2013.

[84] Moualeu, L. P. G., Long, J. A., Stahl, K. A., Ames, F. E., and Suzen, Y. B. 2014. "Midline Heat Transfer and Pressure Measurements on an Incident Tolerant Blade Section for a Variable Speed Power Turbine at Low to Moderate Reynolds Numbers in a Transonic Turbine Cascade," AIAA-2014-3936, Proc. 50th Joint Propulsion Conference, Jul 2014.

[85] Long, J.A, Moualeu, L.P.G., Hemming, N.J., Ames, F.E., Suzen, Y.B. 2015. "Variable Speed Power Turbine Measurements at Low to Moderate Reynolds Numbers in a Transonic Turbine Cascade: Aerodynamic Loss Surveys", GT2015-42504, ASME Turbo Expo, Montreal, Canada, June 2015.

[86] Ameri, A. 2018. "An Implicit LES Simulation of VariableSpeed Power Turbine Cascade for Low Free-Stream Turbulence Conditions," GT2018-77120 For IGTI Turbo Expo Conference, Oslo, Norway, June 2018.

[87] Suder, Kenneth. L., Durbin, K., Giel, P., Poinsatte, P., Thurman, D., and Ameri, A. 2018. "Variable Speed Turbine Technology Development and Demonstration", American Helicopter Society (AHS) International's 74th Annual Forum and Technology Display the Future of Vertical Flight. Phoenix, Arizona, USA, May 14-17, 2018.

[88] Chen, Jen-Ping \& L. Whitfield, David. (1993). NavierStokes calculations for the unsteady flowfield of turbomachinery. 10.2514/6.1993-676.

[89] https://www.aerodynamic-solutions.com/products/code$\underline{\text { leo }}$

[90] https://www.defensenews.com/digital-showdailies/ausa/2016/10/04/army-awards-alternate-conceptengine-development-contract-to-atec/

[91] Suder, K. L. 2012. "Overview of NASA Environmentally Responsible Aviation Project's Propulsion Technology Portfolio", published in the proceedings of AIAA $48^{\text {th }}$ Joint Propulsion Conference, July 2012.

[92] Suder, K. L., Delaat, J., Hughes, C., Arend, D., and Celestina, M. 2013. NASA Environmentally Responsible Aviation Project's Propulsion Technology Phase I Overview and Highlights of Accomplishments. AIAA 2013-0414. Also presented at the FAA CLEEN Consortium Open Session, Oct 27, 2010.

[93] Van Zante, D. E. and Suder, K. L. 2015 "Environmentally Responsible Aviation: Propulsion Research to Enable Fuel Burn, Noise, and Emissions Reduction”, ISABE-2015-

This material is declared work of the U.S. Government and is approved for public release; distribution is unlimited. 
20209, 22nd International Symposium on Air Breathing Engines, Phoenix, Arizona, Oct.25-30, 2015.

[94] Gorrell, Steve, Van de Wall, Alan, Tsung, Fu-Lin, 2005, "Application of Time -Accurate CFD in Order to Account for Blade-Row Interactions and Distortion Transfer in the Design of High Performance Military Fans and Compressors," IEEE Computer Society Users Group Conference, Paper 0-7695-2496-6/05.

[95] Celestina, M. L., Fabian, J. C., and Kulkarni, S. 2012. NASA environmentally responsible aviation high overall pressure ratio compressor research-pre-test CFD. AIAA 2012-4040.

[96] Prahst, P. S., Kulkarni, S., and Sohn. K. H. 2015. Experimental results of the first two stages of an advanced transonic core compressor under isolated and multi-stage conditions. ASME Paper GT2015-42727.

[97] Lurie, David and Breeze-Stringfellow, Andrew, 2015. "Evaluation of Experimental Data from a Highly Loaded Transonic Compressor Stage to Determine Loss Sources,", ASME GT2015-42526, proceedings of the ASME Turbo Expo 2015, June 15-19, 2015, Montreal, Canada.

[98] Peters, Andreas, Spakovszky, Zoltan S., Lord, Wesley K. and Rose, Becky, 2014. "Ultra-Short Nacelles for Low Fan Pressure Ratio Propulsors," ASME GT2014-26369, June 16-20, 2014, Dusseldorf, Germany.

[99] Bozak, Richard F., Hughes, Christopher E., and Buckley, James, 2013. "The aerodynamic performance of an overthe-rotor liner with circumferential grooves on a high bypass ratio turbofan rotor," GT2013-95114, ASME Turbo Expo 2013, San Antonio, TX, June 3-7, 2013.

[100] Van Zante, D. E. 2013. The NASA Environmentally Responsible Aviation Project/General Electric Open Rotor Test Campaign. AIAA 2013-0414.

[101] Van Zante, D. E., F. Collier, A. Orton, S. Arif Khalid, J. P. Wojno, and T. H. Wood. 2014. Progress in open rotor propulsors: the FAA/GE/NASA open rotor test campaign. Aeronaut. J. 118:1181-1213.

[102] Hendricks, E. S., J. J. Berton, W. J. Haller, M. T. Tong, and M. D. Guynn. 2013. Updated assessments of an open rotor airplane using advanced blade designs. AIAA 2013-3628.

[103] Smith, Lance L. 2015. "N+2 and N+3 Low Emissions Combustor Development," presented during the AIAA Science and Technology Forum, Kissimmee, FL, 7 January 2015.

[104] Arend, D. J., G. Tillman, and W. F. O'Brien. 2012. Generation after next propulsor research: robust design for embedded engine systems. AIAA 2012-4041.

[105] Florea, R. V., C. Matalanis, L. W. Hardin, M. Stucky, and A. Shabbir. 2012. Parametric analysis and design for embedded engine inlets. AIAA Paper 2012-3994.

[106] Bakhle, M. A., T. S. R. Reddy, G. P. Herrick, A. Shabbir, and R. V. Florea. 2012. Aeromechanics analysis of a boundary layer ingesting fan. AIAA 2012-3995.

[107] Bakhle, M. A., T. S. R. Reddy, and R. M. Coroneos. 2014. Forced response of a fan with boundary layer inlet distortion. AIAA Paper 2014-3734.
[108] Tillman, G., L. W. Hardin, B. A. Moffitt, et al. 2011. System-level benefits of boundary layer ingesting propulsion. Invited Paper to the 49th AIAA Aerospace Sciences Meeting, Orlando, FL.

[109] Ferrar, A. M., W. F. O'Brien, W. F. Ng, R. V. Florea, and D. J. Arend. 2009. Active control of flow in serpentine inlets for blended wing-body aircraft. AIAA 2009-4901.

[110] Florea, R. V., R. Reba, P. R. VanSlooten, et al. 2009. Preliminary design for embedded engine systems. AIAA 2009-1131.

[111] Arend, David, Wolter, John, Hirt, Stefanie, and Gazzaniga, John, 2019. "Experimental Evaluation of the Performance, Operability, and Aerodynamic Response of a High Bypass Raito Boundary Layer Ingesting Propulsor," ASME GT2019-91709, proceedings of the ASME Turbo Expo 2019, June 17-21, 2019, Phoenix, AZ.

This material is declared work of the U.S. Government and is approved for public release; distribution is unlimited. 